\title{
Der lange Widerstand gegen eine offizielle Heiligenverehrung des Maximos Homologetes ( $\uparrow$ 662) im byzantinischen Reich
}

Abstract: This article addresses the question as to why Maximus the Confessor was first recognized as an official martyr and saint in the imperial Byzantine Church only in the tenth century, although his theology had been accepted by the Sixth Ecumenical Council and his followers began to practice and propagate his cult shortly after his death in 662. The argument begins with a brief description of Maximus' early veneration and then examines the Sixth Ecumenical Council's failure to rehabilitate him by detailing the reasons why this was impossible in 681 and also thereafter. Clearly, in the seventh and eighth centuries the cult of Maximus had its centre outside the empire in parts of Palestinian monasticism. During the iconoclastic era, as in the seventh century, Maximus' name stood once again for opposition to imperial religious policy, for he was held up by those venerating icons as the witness of Tradition to their use. Although during this time iconophile monastic circles in the capital probably fostered his cult as well, his veneration continued to find no official recognition in the ninth century because of on-going division within the church of Constantinople. Only after a great distance in time to the events of the seventh century could official recognition in Byzantium come to Maximus, since the conflicts of that earlier era were no longer relevant. In this context, the 'Holy Confessor Maximus' underwent a process of acceptance by the Byzantines who anchored his biography in Constantinople. As a result, the actual circumstances of the monothelete controversy have ultimately been obscured.

Adresse: Prof. Dr. Heinz Ohme, Humboldt-Universität zu Berlin, Theologische Fakultät, Burgstr. 26, 10178 Berlin, Deutschland; Heinz.Ohme@rz.hu-berlin.de 
Im Jahre 662 wurde Maximos Homologetes (579/80-662) ${ }^{1}$ mit seinen beiden Schülern Anastasios Monachos († 662) $)^{2}$ und Anastasios Apokrisiarios († 666) $)^{3}$ in Konstantinopel als Abschluss eines Hochverratsprozesses wegen „Blasphemie und Hochverrat“ ${ }^{\star 4}$ zu öffentlicher Auspeitschung, Amputation der Zunge und der rechten Hand ${ }^{5}$ sowie endgültiger Exilierung verurteilt, nachdem eine Synode sie zuvor anathematisiert hatte. In einem ersten Verfahren am 16. und 23./24. Mai 655 gegen Maximos und Anastasios Monachos waren beide in die Verbannung geschickt worden, wo sie getrennt voneinander ca. sieben Jahre an verschiedenen Orten Thrakiens lebten. Anastasios Apokrisiarios war bereits als römischer Apokrisiar i.J. 648 wegen seiner Weigerung, den gerade erlassenen kaiserlichen Typos ${ }^{6}$ anzuerkennen, verurteilt und nach Trapezunt in die Verbannung geschickt worden. Die Gründe für dieses radikale Vorgehen gegen den palästinischen Mönch $^{7}$

1 PmbZ Nr. 4921.

2 PmbZ Nr. 237.

3 PmbZ Nr. 238.

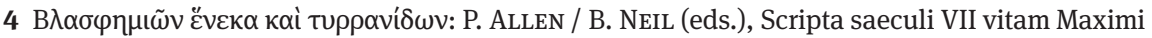
Confessoris illustrantia, una cum latina interpretatione Anastasii Bibliothecarii iuxta posita. CCSG, 39. Turnhout/Leuven 1999, 149, 825.

5 Es handelt sich hierbei um die im römischen Recht üblichen Spiegelstrafen: Vgl. S. N. TROIANos,

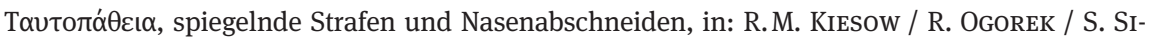
MiтIS (Hrsg.), Summa. Festschrift D. Simon zum 70. Geburtstag. Frankfurt/M. 2005, 569-578. 6 Dieses Gesetz untersagte im Sinne eines Moratoriums jeden weiteren öffentlichen Streit über die Anzahl der Willen in der Person Jesu. Zum Typos vgl. F. Winkelmann, Der monenergetisch-monotheletische Streit. Berliner Byzantinistische Studien, 6. Frankfurt/M. 2001, Nr. 106; zu seiner kirchenpolitischen und theologischen Bedeutung vgl. H. OHмE, Oikonomia im monenergetischmonotheletischen Streit. ZAC 12 (2008) 308-343, hier 316-321. Durch den Typos war explizit ein älteres kaiserliches Gesetz, die von Kaiser Herakleios (610-641) im Jahre 638 (?) erlassene Ekthesis, aufgehoben worden, die die monotheletische Lehre vertreten hatte. Auch diese durfte seit 648 nicht mehr öffentlich vertreten werden. Zur Ekthesis vgl. Winkelmann, ebd. Nr. 50; Ohme, ebd. 335-336. 314-316. Рн. Воотн, Crisis of empire: doctrine and dissent at the end of late antiquity. Berkeley u.a. 2013, 239-241, hat unter Berufung auf M. JANKowIAK, Essai d'histoire politique du monothélisme, Diss. Paris/Warschau 2009 [ungedr.], 146-149, die Ekthesis m.E. zutreffend auf 636 datiert.

7 Die gegenüber der syrischen Vita Maximi des 7. Jh.s (S. BRock, An early Syriac Life of Maximus the Confessor. Analecta Bollandiana 91, 1973, 299-346 = DERS., Syriac perspectives on late antiquity. London, 1984, Nr. XII) erstmals in der griechischen Vita Maximi des 10. Jh.s (BHG 1234) begegnende konstantinopolitanische Herkunft, Jugend und Bildung des Maximos ist nach den neuesten Forschungen endgültig nicht mehr haltbar. Vgl. CH. Boudignon, Maxime le Confesseur était-il Constantinopolitain?, in B. Janssens / B. Roosen / P. van Deun (eds.), Philomathestatos. Studies in Greek and Byzantine Texts Presented to J. Noret for his 65th Birthday. Orientalia Lovaniensia Analecta, 137. Leuven u.a. 2004, 11-43; B. Roosen, Maximi Confessoris Vitae et Passiones Graecae: the development of a hagiographic dossier. Byz 80 (2010) 408-460; M. 
und „greatest of Byzantine theologians“8 sowie seine Schüler erklären sich nicht allein aus dem anhaltenden theologischen Widerstand gegen die von den Kaisern Herakleios $(610-641)^{9}$ und Konstans II. $(641-668)^{10}$ geförderte sog. monenergetisch-monotheletische Religionspolitik. ${ }^{11}$ Vielmehr müssen die in diesem Zusammenhang betriebenen politischen und kirchenpolitischen Machenschaften ${ }^{12}$ des um Maximos versammelten und „international“ agierenden palästinischen Mönchskollektivs ${ }^{13}$ in Rechnung gestellt werden. ${ }^{14}$ Angesichts der kirchenpolitischen Kehrtwende unter Konstantin IV. $(668-685)^{15}$ und der Rezeption zentraler Theologumena des maximianischen Dyotheletismus durch das VI. Ökumenische Konzil (680/81) war man früher mit Selbstverständlichkeit davon ausgegangen, dass diese theologische Anerkennung mit einer persönlichen Rehabilitierung des Maximos einhergegangen sei und die griechische Vita Maximi (BHG 1234) ${ }^{16}$ deshalb im Umfeld des III. Constantinopolitanums anzusiedeln sei. ${ }^{17}$ Von einer Rehabilitierung des Maximos und seiner Schüler i.J. 680/81 kann allerdings keine Rede sein. Vielmehr ist festzustellen, dass der Name Maximos in den gesamten Konzilsakten nicht ein einziges Mal erwähnt wird. Ausgehend von dieser Beob-

JAnkowiak / Рн. Воотн, A new date-list of the works of Maximus the Confessor, in P. Allen / B. Neil (eds.), The Oxford Handbook of Maximus the Confessor. Oxford 2015, 19-83, hier 19-21. 8 So A. Louth, Maximus the Confessor. London 1996, Klappentext. Zu Maximos jetzt umfassend: Allen/NeIL, Handbook (wie oben Fußnote 7).

9 W.E. KaEgi, Heraclius, Emperor of Byzantium. Cambridge 2003.

10 PmbZ Nr. 3691.

11 Vgl. Winkelmann (wie oben Fußnote 6); zum Monenergismus: Chr. Lange, Mia Energeia. Untersuchungen zur Einigungspolitik des Kaisers Heraclius und des Patriarchen Sergius von Constantinopel (Studien und Texte zu Antike und Christentum 66), Tübingen 2012.

12 W. BRANDES, „Juristische“ Krisenbewältigung im 7. Jahrhundert? Die Prozesse gegen Papst Martin I. und Maximos Homologetes, in: L. Burgmann (Hrsg.), Fontes Minores X (1998) 141-212; DERs., Konstantin der Große in den monotheletischen Streitigkeiten des 7. Jh.s, in E. KountouraGalake (Hrsg.), The Dark Centuries of Byzantium (7th-9th. c.). Athen 2001, 89-107.

13 Vgl. CH. Boudignon, Le pouvoir de l'anathème ou Maxime le Confesseur et les moines palestiniens du VIIe siècle, in A. Camplani / G. Filoramo (Hrsg.), Foundations of power and conflict of authority in late antique monasticism. Orientalia Lovaniensia Analecta, 157. Leuven u.a. 2007, $245-274$.

$14 \mathrm{Zu}$ diesen Aktionen im Detail s. unten S. 123-124.

15 PmbZ Nr. 3702.

$16 P G$ 90, 68-109.

17 So R. DeVReEsSe, La vie de Maxime le confesseur et ses recensions. Analecta Bollandiana 46 (1928) 5-49, hier 44; genauso noch H.-G. BECK, Kirche und theologische Literatur im byzantinischen Reich. München 1959, ²1977, 463: „Die Biographie des Maximos dürfte um 680 entstanden sein, also etwas zur Zeit der Synode, welche die Streitigkeiten fürs erste beendete, die Maximos das Leben gekostet hatten.“ 
achtung hat W. LACKNER bereits 1967 nachgewiesen, ${ }^{18}$ dass die griechische Vita Maximi (BHG 1234) mit ihren Details zur angeblichen konstantinopolitanischen Herkunft des Maximos, die das Maximosbild bis in die Gegenwart bestimmt haben, erst im 10. Jh. ihre endgültige Gestalt gewonnen hat. Der Herausgeber der noch ausstehende Edition der verschiedenen hagiographischen Varianten einer Passio oder/und Vita Maximi in Menologien, Synaxaren u.a.m., B. Roosen, hat im Jahre 2010 eine umfassende Untersuchung zu den literarischen Abhängigkeiten dieser seitdem vieldiskutierten Quellen vorgelegt. ${ }^{19}$ Zeitlich am Ende steht die Passio des Menologium Imperiale A (BHG 1235) aus dem 11. Jh. mit dem Eintrag am 13. August. ${ }^{20}$ Diese Passio ist abhängig von der Passio des Synaxarium Constantinopolitanum, das H. DeleHAYE in der späteren Version des 12. Jh.s ediert hat. ${ }^{21}$ Beim Synaxarium handelt sich in der Erstgestalt um eine Auftragsarbeit Kaiser Konstantins VII. Porphyrogennetos (913/945-959). Das von J. MATEos edierte Typikon der Hagia Sophia hat den Eintrag ebenfalls am 13. August. ${ }^{22}$ Die griechische Vita Maximi (BHG 1234) mit ihren drei Rezensionen ${ }^{23}$ gehört mit der ältesten Fassung des 10. Jh.s nach Konstantinopel. ${ }^{24}$ Diese vier Quellen bezeugen,

18 W. LACKNER, $\mathrm{Zu}$ Quellen und Datierung der Maximosvita ( $B H G^{3}$ 1234). Analecta Bollandiana 85 (1967) 285 -316, hier 287.

19 Roosen, Vitae (wie oben Fußnote 7). Zum Forschungsstand bis 1998 vgl. W. BRANDES, Anmerkungen zu den Quellen zur Biographie des Maximos Homologetes, in: PmbZ Prolegomena. Berlin/New York 1998, 171-179.

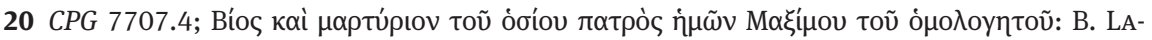
TYŠEV, Menologii anonymi Byzantini saeculi X quae supersunt, Fasc. alter. Petropolis 1912 (= Subsidia Byzantina lucis ope iterata XII. Leipzig 1970), 273-276. Die Passio endet mit einer Invocatio Maximi: ebd. 276, 8-15. Roosen, Vitae (wie oben Fußnote 7) 411-413. Dieses Menologium ist Kaiser Michael IV. Paphlagon (1034-1041) gewidmet, gehört also an den Anfang des 11. Jh.s., und ist ,the last example of systematic hagiographical production during the Byzantine era“: Roosen, ebd. 412.

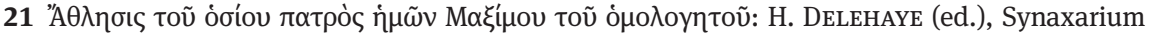
Ecclesiae Constantinopolitanae e codice Sirmondiano. Propylaeum ad Acta Sanctorum Novembris. Brüssel 1902, 409, 2 - 410, 17; 887, 2 - 890, 6. Roosen, Vitae (wie oben Fußnote 7) 414-417. Der Synaxareintrag erfolgt am 13. August, erst in der späteren Fassung des sog. „Synaxarium Sirmondianum“ tritt erstmals der 21. Januar als Gedenktag des Maximos hinzu.

22 J. Mateos, Le Typicon de la Grande Église. Orientalia Christiana Analecta, 165. Roma 1962, 368-369. Allerdings fehlt in der von MAtEos edierten Handschrift das folio mit dem Text der Passio. Es ist derselbe Codex Hierosolymitanus Sanctae Crucis 40 (s. X-XI), aus dem DeleHAYE das Synaxarium edierte.

$23 \mathrm{Zu}$ den drei „Rezensionen“ dieser Vita vgl. B. NeIL / P. AlLEN (Hrsg.), The Life of Maximus the Confessor. Recension 3. Early Christian Studies, 6. Brisbane 2003.

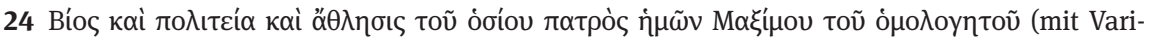
anten!), Rec. II: PG 90, 68 A1 - 109B9; Rec. III: NEIL/ALLEN, Life (wie oben Fußnote 23); Roosen, Vitae (wie oben Fußnote 7) 435-439 steht der seit Devreesse gängigen Einteilung der hand- 
dass im 10. Jh. der Maximoskult auch in Konstantinopel offiziell fest installiert gewesen ist. ${ }^{25}$

Wie aber ist der Weg einer Rehabilitierung des Maximos bis $\mathrm{zu}$ seiner reichskirchlichen Anerkennung als Märtyrer mit der Folge eines entsprechenden Kultes in den bald 300 Jahren dazwischen verlaufen? Welche Hindernisse stellten sich dem entgegen? Warum hat sich der unmittelbar nach dem Tode des Maximos und Anastasios Monachos unter ihren Anhängern einsetzende Märtyrer- und Heiligenkult offensichtlich nach 681 nicht schnell im byzantinischen Reich durchsetzen können? Der Beantwortung dieser Fragen ist die nachfolgende Untersuchung gewidmet. Dazu wird zuerst der von den Maximianern umfangreich propagierte und umgehend bereits nach 662 praktizierte Maximoskult dargestellt (I). Ein zweites Kapitel fragt nach den Gründen, warum es im byzantinischen Reich nach 681 nicht zu einer schnellen kultischen Verehrung eines Märtyrers Maximos gekommen ist (II). Kapitel III schildert die Hindernisse, die in der Epoche des Bilderstreites zusätzlich einer offiziellen Rehabilitierung des „Confessors“ entgegenstanden. Im letzten Kapitel werden die Entwicklungen geschildert, die im 10. Jh. eine „modifizierte“ byzantinische „Nostrifizierung“ des Maximos ermöglichten.

\section{Der Beginn des Märtyrerkultes von Papst Martin I. und Maximos bei deren Schülern und Anhängern}

Die drei im Jahre 662 Verurteilten erreichten verstümmelt das Exil in Lazikē/ Kaukasus am 8. Juni 662, wo sie auf verschiedene byzantinische Festungen verteilt wurden. Anastasios Monachos starb an den Folgen der Verstümmelung am 22./ 24. Juli 662, Maximos am 13. August 662. Allein Anastasios Apokrisiarios überlebte beide um mehr als vier Jahre bis zum 11. Oktober 666. Papst Martin I. (649-653; † $655)^{26}$, der Konzilspapst der Lateransynode von 649, war bereits am 17. September 653 in Rom gefangengenommen worden und am 19. Dezember 653 in Konstanti-

schriftlichen Tradition in drei „Rezensionen“ allerdings kritisch gegenüber. Zur Lokalisierung in Konstantinopel Roosen ebd. 450-451. Die Vita endet ebenfalls mit einer Invocatio Maximi. 25 Auf dieser Grundlage basiert der Eintrag des Maximos als Confessor und Heiliger im orthodoxen und römisch-katholischen Heiligenkalender. Festtage sind der 13. August (röm.-kath. und orth.) und 21. Januar (orth.). Zum orthodoxen Gedenktag s. unten S. 149-150 mit Fußnoten 233 234.

26 PmbZ Nr. 4851. 
nopel wegen Hochverrats zum Tode verurteilt worden. Begnadigt und nach Cherson/Krim verbannt starb er dort am 16. September 655.

Anastasios Apokrisiarios hat in seinem letzten Lebensjahr zwischen dem 1. September 665 und dem 11. Oktober 666 einen Brief ${ }^{27}$ an den aus Gangra stammenden Mönchspriester Theodosios geschrieben, der wie sein Bruder, der

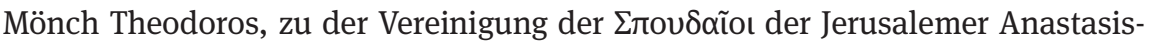
Kirche gehörte. ${ }^{28}$ Beide Brüder gehörten auch zum engsten Zirkel um Maximos. Das griechische Original des Briefes wurde erst 1955 von E. DEvREESSE ediert; ${ }^{29}$ einige Teile des Schreibens sind nur in der lateinischen Übersetzung des Anastasius Bibliothecarius erhalten.

Der Verfasser macht eingangs klar, dass er der Aufforderung von Prov

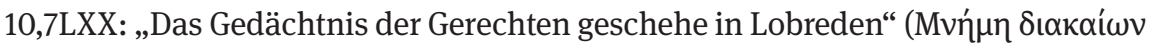

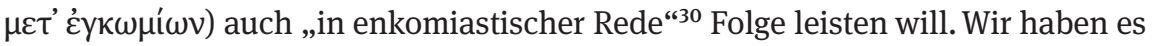
also mit einer enkomiastischen Darstellung zu tun, mit der der schwerverletzte, seinem Tod entgegengehende Autor der Mneme der verstorbenen „Gerechten“ dienen will. Nach der Beschreibung der Ankunft der Gruppe der Verurteilten in Lazikē schildert der Brief zuerst das weitere Schicksal des Christi Dei martyr ${ }^{31}$ Maximos. Dieser sei vor seinem Tode einer divina visio gewürdigt worden, in der ihm sein Todestag ${ }^{32}$ offenbart worden sei, was er auch anderen an seinem Ver-

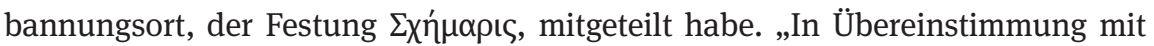
seiner Weissagung“ (secundum diuinum eius uaticinium) sei er dann an diesem Tage verstorben. Hinzugekommen sei noch ein aliud miraculum, das sich dann divinitus am Grabe des Maximos ereignet habe und von vielen usque in praesens beobachtet und weitergesagt werde und sogar die Aufmerksamkeit führender

27 Epistula Anastasii Apocrisarii ad Theodosium Gangrensem (CPG 7733): ALLEN NeIL, Scripta (wie oben Fußnote 4) 173-189 (im Weiteren = Ep. Anast.). Zum Brief ebd. XX-XXII; DIES., Maximus the Confessor and his companions. Documents from exile. Edited and translated. Oxford 2002, 40-41; Winkelmann, Streit (wie oben Fußnote 6) Nr. 151.

$28 \mathrm{Zu}$ den beiden Spoudaioi vgl. PmbZ Nr. 7816; 7439. Die Vereinigung der Spoudaioi hatte neben Jerusalem auch eine Niederlassung in Konstantinopel; mit den zuletzt von J. NoRET, À qui était destinée la lettre BHG 1233d d'Anastase l'Apocrisiaire? Analecta Bollandiana 118 (2000) 37 42) vorgetragenen Argumenten spricht alles dafür, den Adressaten in Jerusalem zu lokalisieren. Zur Vereinigung der Spoudaioi vgl. S. PÉTRIDÈs, Le monastère des Spoudaei à Jérusalem et les Spoudaei de Constantinople. EO 4 (1900/1901) 225-231; 7 (1904) 341-348.

29 R. Devreesse, La lettre d'Anastase l'Apocrisiaire sur la mort de S. Maxime le Confesseur et ses compagnons d'exil. Texte grec ińedit. Analecta Bollandiana 73 (1955) 5-16.

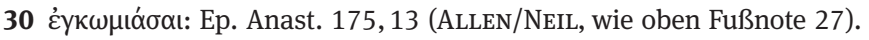

31 Ep. Anast. 176, 83 (Allen/NeiL).

32 Der Brief macht die Angabe: Tertio decimo die Augusti mensis huius instantis quintae indictionis, feria septima $=13$. August 662: Ep. Anast. 176,86-88 (Allen/NeIL). 
Kreise gefunden habe: „Drei Lichter erleuchten an einzelnen Nächten das hl. Grab jenes heiligen Märtyrers Maximos.“33 Dies sei „würdig, euch Heiligen und durch euch allen, die dort heilig sind, in Briefen mitgeteilt zu werden“. Denn dies geschehe „zum Ruhm und Lobe Gottes, der in seinen Heiligen Wunder wirkt und das Gedächtnis derer verherrlicht, die ihn rechtgläubig und aufrichtig verherrlichen (1Kö 2,30 LXX).“34 Indem anschließend noch Ps 67,36 LXX zitiert wird (,Wunderbar ist Gott in seinen Heiligen“335), sind damit drei im Kontext der Heiligenverehrung vielzitierte Schriftstellen aufgerufen worden.

Nachdem Anastasios sodann sein eigenes Schicksal schildert, kommt er auf Papst Martin I. und die Lateransynode von $649 \mathrm{zu}$ sprechen, die ,auf heilige Anordnung dieses heiligen Märtyrers und apostolischen und an der Spitze stehenden Papstes Martin im Alten Rom versammelt worden war." ${ }^{\text {"36 }}$ Er sieht sich, Martin und Maximos als Opfer einer Verfolgung, die „uns und Gott“ ungerechterweise gelte ${ }^{37}$ und die einzuordnen sei in jene Verfolgungen, Exile und Leiden, die den „heiligen Propheten, Aposteln und Lehrern“ seit Beginn der Verkündigung zuteil wurde. ${ }^{38}$

Bei dem sog. Hypomnesticon Theodori Spudaei (CPG 7968) $)^{39}$ handelt es sich um eine Denkschrift über das Schicksal aller nach den Prozessen von 653, 655 und 662 Verbannten, zu denen außer den bisher Genannten auch noch die beiden Schüler des Anastasios Apokrisiarios, Theodoros und Euprepios, ${ }^{40}$ gehören. Der Text wurde nach dem Eintreffen von Ep. Anast. bei Theodosios Spudaios von

33 Tres lampades luciferae per singulares noctes sanctum sancti illius martyris Maximi monumentum illustrant: Ep. Anast. 178,101-102 (ALLEN/NeIL).

34 Dignum est et uobis quoque sanctissimis er per uos omnibus qui ibidem sunt sancti, per litteras fieri manifestum, in gloriam et laudem Dei qui facit mirabilia in sanctis suis et glorificat memoriam eorum qui se orthodoxe ac sincere glorificant: Ep. Anast. 176, 96 - 178,100 (ALLEN/NEIL).

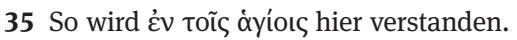

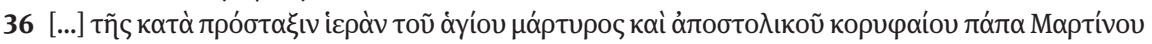

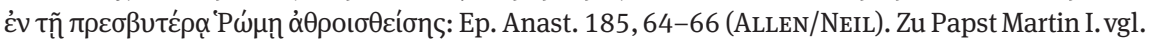
PmbZ Nr. 4851.

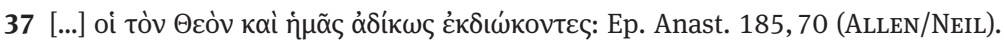

38 Ep. Anast. 187, 82-86 (Allen/NeIL). Der Brief enthält am Ende ein Scholion, das Theodosios von Gangra zugeordnet wird. Dort heißt es, dass ,unser heiliger Vater und Märtyrer Anastasios“ an Sonntag, dem 11. Oktober 666 in dem Augenblick verstarb, als bei der Liturgie der Ruf „Das Heilige den Heiligen!“ erklang (ebd. 189 App.). Es handelt sich um jenen Ruf, der in der orthodoxen Liturgie vor Beginn der Kommunion die Anaphora abschließt.

39 ALLEN/NeIL, Scripta (wie oben Fußnote 4) 191-227. Im Weiteren = Hypomn.

$40 \mathrm{Zu}$ beiden vgl. PmbZ Nr. 1721. 7301. 
diesem und seinem Bruder Theodoros Spudaios verfasst. ${ }^{41}$ Der Letztere war Augenzeuge der Ankunft des gefangengenommenen Papstes Martin I. in Konstantinopel und dessen Briefpartner während seines Exils in Cherson. Nach dessen Tod war er 655/56 zur Verehrung des päpstlichen Grabes nach Cherson gereist, um dann das Schicksal Martins in den Narrationes de exilio Sancti papae Martini zu schildern. ${ }^{42}$ Im Jahre 668 reiste er mit seinem Bruder nach Lazike, um danach diese Denkschrift zu verfassen. Der Text hat eine Überschrift, die den Eindruck erweckt, dass es sich um „a liturgical rubric“ handelt. ${ }^{43}$

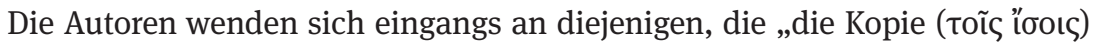
des beigefügten heiligen Briefes des Heiligen (sc. Anastasios Apokrisiarios)“ gelesen haben. ${ }^{44}$ Ep. Anast. ist also kopiert und dem Hypomn. beigefügt worden. Der inzwischen verstorbene Anastasios wird jetzt als „unser heiliger Vater und Lehrer“ und „wahrhaft großer neuer Bekenner und Märtyrer der Wahrheit“ bezeichnet. ${ }^{45}$ Seine Heiligkeit wird hauptsächlich durch die Tatsache erwiesen, dass die Ep.

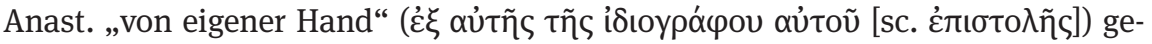
schrieben wurde, obwohl ihm diese doch amputiert worden war. Dies sei ein

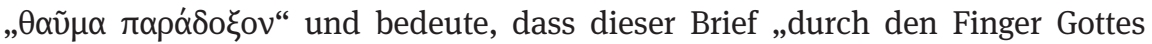

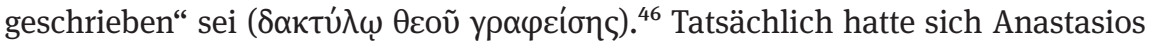
eine aus dünnen Hölzern bestehende Prothese an seinen Armstumpf gebunden, um so schreiben zu können. Dafür werden hochstehende „Augenzeugen“ namentlich benannt, die dies den Reisenden berichtet hätten. ${ }^{47}$ Damit nicht genug habe Anastasios noch weitere Schriften hinterlassen, von denen man „mit seiner

41 Sie geben sich im Text selbst als Autoren zu erkennen: Hypomn. 217, 290-292 (ALLEN/NEIL). Zum Text vgl. AlLEN/NeIL, Scripta (wie oben Fußnote 4) XXII-XXIII; DiES., Documents (wie oben Fußnote 27) 41-42: Winkelmann, Streit (wie oben Fußnote 6) Nr. 154.

42 BHL 5593-94: B. NeIL, Seventh-century popes and martyrs. The political hagiography of Anastasius Bibliothecarius. Studia Antiqua Australiensia, 2. Turnhout 2006, 95-103. 166-233; eingefügt darin ist die Commemoratio eorum quae saeuiter et sine Dei respectu acta sunt a veritatis adversarii in sanctum et apostolicum nouum reuera confessorem et martyrem Martinum papam Romae per epistulam cuiusdam Christianissimi directam his qui sunt in Occidente seu Romae et Africa orthodoxis patribus: ebd. 182-220; vgl. WinkELMAnN (wie oben Fußnote 6) Nr. 138.

43 Allen/NeIl, Documents (wie oben Fußnote 27) 188 Anm. 1. Die Überschrift lautet: 'Iotopí $\alpha$

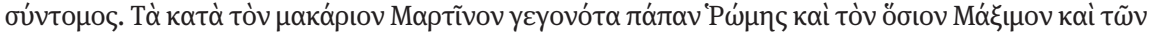

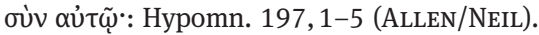

44 Hypomn. 199, 37 (ALLEN/NeIL).

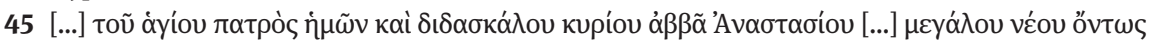

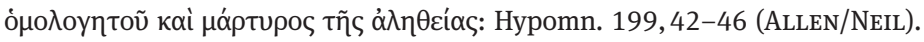

46 Hypomn. 199, 40-42 (Allen/Neil).

47 Hypomn. 201,75-82 (AlLEN/NeIL). Genannt werden Lebarnikios, Patrikios von Lazikē, und Theodoros, Protasekretis des Prätorianerpräfekten von Konstantinopel (PmbZ, Nr. 4236. 7311). 
Erlaubnis (sc. des Anastasios!) auch Teile durch die Gnade Gottes zum Erbe“ an sich nehmen konnte. ${ }^{48}$

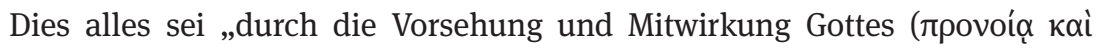

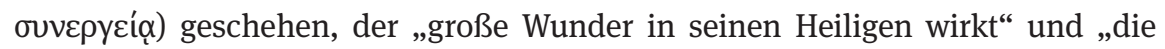
verherrlicht, die ihn verherrlichen“ (Ps 135, 4 LXX; 67, 36 LXX;1Kön 2, 30 LXX). ${ }^{49}$ Die Verfasser scheuen sich nicht, die schon zuvor gezogene Analogie zur Beschriftung der Gesetzestafeln des Dekaloges nun nochmals explizit zu formulieren: diese Schriften seien geschrieben „mit dem Finger Gottes wie beim großen Mose. “50

Das Hypomn. berichtet sodann vom Schicksal der beiden Brüder Theodoros und Euprepios, die mit Papst Martin nach Cherson verbannt worden waren. Als die beiden Spudaioi nach Cherson gereist waren, um dort das Grab des bereits verstorbenen Euprepios und ,des wahrhaft ökumenischen Papstes und Großmärty-

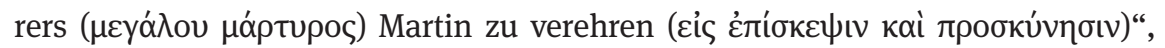

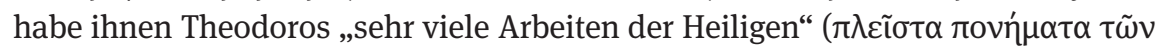

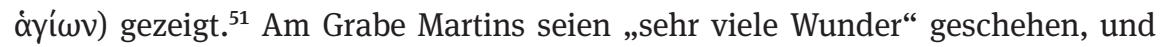
Theodoros habe ihnen schließlich „ein Stück des Halstuches, das für sie vom Heiligen zurückgelassen worden war“, sowie einen seiner Schuhe, „die niemand anderes als der heilige römische Papst trägt“, gegeben. ${ }^{52}$ Der Leidensweg des Papstes nach seiner Gefangennahme wird mit den Worten eingeleitet: „Er lieferte sich selbst aus und begehrte und ersehnte das Martyrium für Christus ganz und gar.“53 Am Ende des Hypomn. heißt es sogar, dass Martin sich „als Opfer für das fromme Volk hingegeben hat und dabei in allem den Kampfrichter Christus unseren Gott und den Ersten der Apostel, Petrus, nachgeahmt hat und ihnen gefolgt ist. " ${ }^{\circ 4}$

Danach kommt das Hypomn. auf den „heiligen Maximos“ zu sprechen, „ihren vielgepriesenen, unübertrefflichen, hochweisen großen Mitverteidiger und größ-

48 Hypomn. 203, 92-96 (ALLEN/NEIL).

49 Hypomn. 203,99-102 (ALLEN/NEIL).

50 Hypomn. 203,98-99 (Allen/NeiL). Auch hier wird die Heiligkeit des Anastasios mit der Koinzidenz seines Todes und dem Ruf: „Das Heilige den Heiligen!“ während der Anaphora bestätigt: ebd. 205,116-120.

51 Hypomn. 209, 173-176 (AlLEN/NeIL).

52 Hypomn. 209, 179-182 (ALlEN/NeIL).

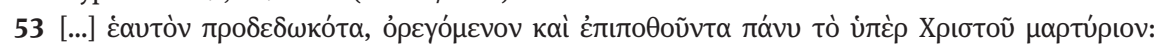
Hypomn. 209, 184-185 (ALlEN/NEIL).

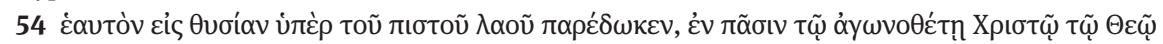

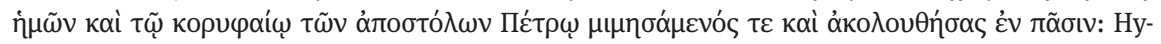
pomn. 225, 400-403 (ALLEN/NeIL). 
ten Mitmärtyrer." ${ }^{55}$ Hier ist es nun das Wunder am Grabe, das zuerst ausführlich zur Sprache gebracht wird. Die in Ep. Anast. erwähnten Lichter lassen das Grab nun „in jeder Nacht von dem Tag an, als er entschlief, bis jetzt und für immer“ erstrahlen. Diese Lichter „bringen allen Klarheit und machen seinen freimütigen Zugang bei Gott ( $\pi \alpha \rho \rho \eta \sigma i ́ \alpha)$ offensichtlich. ${ }^{* 56}$ Zeugen dafür werden in großer Zahl benannt, die sogar „unter Schwur“ das Gesehene berichtet haben. ${ }^{57}$ Schließlich

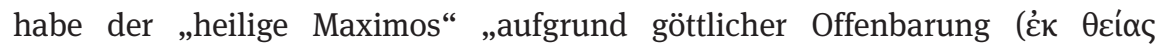

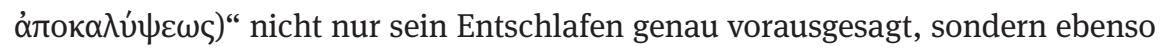
„vor etlichen Jahren bereits sein heiliges Martyrium in Christus unserem Gott für die Wahrheit. “58

Zum Schluss berichten die Verfasser, dass sie „handgeschriebene Schriften“ des Anastasios Apokrisiarios einschließlich seiner Schreibprothese „als wirklich

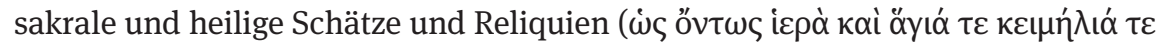

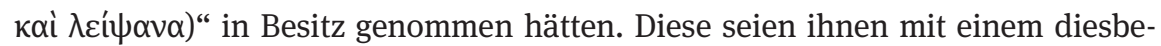
züglichen Schreiben vom Abt des dortigen Johannesklosters in der AnastasisKirche übergeben worden..$^{59}$ Ebenso habe man bereits, als man Maximos und Gefährten i.J. 662 in die Verbannung begleitet habe, „einige der von ihnen während ihres Leidensweges getragenen Kleidungsstücke von ihren eigenen Händen

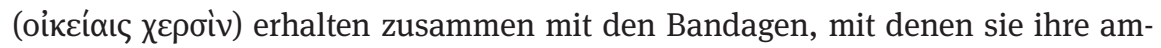
putierten Hände zur Heilung umwickelt hatten, die geheiligt und von ihrem wertvollen Blut rotgefärbt waren. “60 Man habe entschieden, „beide zusammen zu kommemorieren“, „weil sie ein und dasselbe geworden sind in ihrem Kampf ( $\alpha \beta \lambda \eta \sigma \iota \varsigma)$ für den heiligen und wahrhaft orthodoxen Glauben“. ${ }^{61}$ Das Hypomn. schließt mit der Information, dass man für diejenigen, die die Schriften der Märtyrer selbst lesen wollen, diese „in mehreren $\beta$ í $\beta \lambda$ o und tó $\mu$ o “ abgeschrieben habe. ${ }^{62}$ Die Leser werden noch um inständiges Gebet ersucht, damit diese Verfolgung, die schlimmer sei ,als alle vorhergehenden heidnischen und häretischen Verfolgungen“, zu Ende gehe. Man möge „in unserem heiligen orthodoxen und

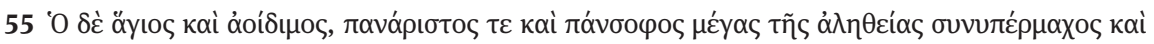

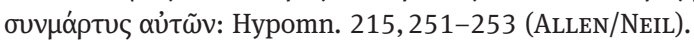

56 Hypomn. 215, 256-257 (Allen/NeiL).

57 Hypomn. 215, 259 (ALlEN/NEIL).

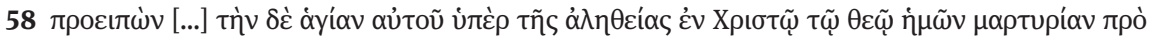

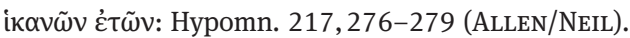

59 Hypomn. 217, 284-297: 290-291 (ALLEN/NEIL).

60 Hypomn. 219, 324-328 (ALLEN/NEIL).

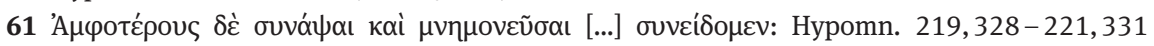
(ALLEN/NEIL).

62 Hypomn. 223, 359-367 (AlLEN/Neil). 
makellosen Glauben der Christen, dem einzig katholischen und apostolischen“, verharren. $^{63}$

Der kurze Text Contra Constantinopolitanos ${ }^{64}$ ist von einem anonymen Anhänger des Maximos nach 662 geschrieben worden, ${ }^{65}$ ohne dass sich der Zeitraum näher bestimmen lässt. Ausweislich seiner Überschrift war der Verfasser Mönch

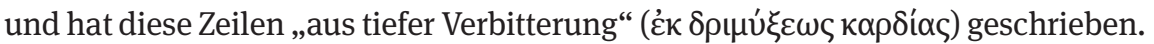
Tatsächlich handelt es sich um eine Anklageschrift in schneidender Schärfe gegen die Einwohner der Hauptstadt, die für die Verurteilung des Maximos und seiner Schüler verantwortlich gemacht werden. Gleich am Anfang werden der Kaiser und zwei der bei der Disputatio Bizyae ${ }^{66}$ Anwesenden, Bischof Theodosios von Kaisareia und der Patrikios Epiphanios, verbal beleidigt, „weil sie dem heiligen Maximos, dem dritten Theologen, Zunge und rechte Hand abgeschnitten haben“

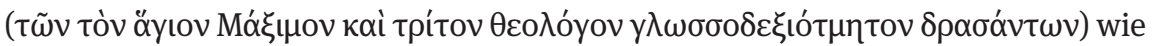
den Anastasioi, seinen beiden Schülern. ${ }^{67}$ Ist hier mit der Bezeichnung ,dritter Theologe“ ein Ehrentitel gemeint, der Maximos neben dem Evangelisten Johannes und Gregor von Nazianz zugewiesen wird, ${ }^{68}$ oder nur eine Auflistung als dritter „Theologe“ neben den beiden Anastasioi? Beide Schüler sind literarisch tätig gewesen, ${ }^{69}$ aber jeder von ihnen hätte mit Sicherheit eine Vorordnung als erster und zweiter „Theologe“ vor Maximos strikt zurückgewiesen. Klarheit in diese Frage bringt eine weitere Textpassage. Denn der Verfasser stellt sogleich die rhetorische Frage, was in ,seinen bewährten theologischen und geistlichen Lehren“ und „in den ethischen, gnostischen und exegetischen Gedanken“ nicht schriftgemäß sei, um dann zentrale Werke des Maximos aufzuzählen, die ,je-

63 Hypomn. 225, 386-392. 410-412 (ALLEN/NEIL).

64 Allen/NeIL (Hrsg.), Scripta saeculi VII (wie oben Fußnote 27), 229-232; DiEs., Documents (wie oben Fußnote 27) 172-175. Im Folgenden: Contra Const.

65 „It could stem from the same circle of monks engaged in compiling anti-monothelite material, who were possibly also the authors of the Doctrina Patrum": ALLEN/NEIL, Documents (wie oben Fußnote 27) 43. Die älteste Fassung der Doctrina Patrum ist zwischen 662 und 680 entstanden, vgl. F. Diekamp, Doctrina Patrum de incarnatione verbi. Ein griechisches Florilegium aus der Wende des 7. und 8. Jh. (1907), 2. Auflage mit Korrekturen und Nachträgen v. B. PHANougakis, hrsg.v. E. ChrYsos. Münster 1981, LXXIX.

$66 \mathrm{Zu}$ diesem Gespräch einer kaiserlichen Gesandtschaft mit Maximos während seiner ersten Verbannung in Bizye s.unten S. 134-135, Fußnote 79.

67 Contra Const. 230,16-18 (ALLEN/NEIL).

$68 \mathrm{Im}$ selben Zeitraum hat Gregorios Presbyteros (6./7.Jh.) in seiner Vita Greg. Naz. der bereits geläufigen Verwendung des Ehrentitels „Theologe“ entsprechend festgehalten, dass nur Gregor

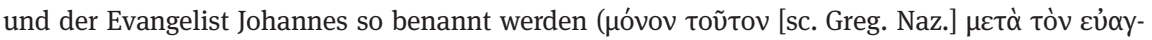

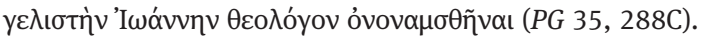

69 Vgl. PmbZ Nr. 237. 238. 
dermann bewundert hat, bewundert und weiterhin bewundern wird“ “ ${ }^{70}$ Es ist m. E. offensichtlich, dass hier im Rahmen der propagierten Märtyrerverehrung mit der theologischen Brillanz des Maximos in allen theologischen Disziplinen argumentiert wird und ihm von seinen Anhängern der Ehrenname eines „Theologen“ zusammen mit dem Evangelisten Johannes und Gregor von Nazianz zugelegt wurde.

In der Schlusspassage steigert der Verfasser nochmals seine Vorwürfe gegen die Konstantinopolitaner und ihre Stadt, die nun das „siebenhügelige Babylon“ genannt wird, ${ }^{71}$ von dem ,jeder Gerechte“ verfolgt wird, das die Rechte - „ich meine die Wahrheit Gottes“ - abschneidet, und über das Gottes gerechtes Gericht kommen wird. „Das ewige Reich Christi aber wird die Bekenner, die nichts weniger als Märtyrer sind, aufnehmen. Mögen auch wir dies erlangen - wenn ich es zu sagen wagen darf - durch ihre (Gott) wohlgefälligen Fürbitten. Amen“. ${ }^{72}$

Das Hypomn., das zusammen mit einer Kopie der Ep. Anast. seit Ende 668/ Anfang 669 verbreitet wurde, ist von der Absicht seiner Verfasser bestimmt, das Gedächtnis der Hauptprotagonisten der dyotheletischen Opposition und ihres theologischen Werkes sowie ihres Widerstandes gegen die kaiserliche Religionspolitik nach ihrem Tod lebendig zu erhalten, um so den Kampf für die beanspruchte Wahrheit des maximianischen Dyotheletismus weiterführen zu können. Dazu werden nicht nur detaillierte Berichte über den Leidensweg der Verurteilten bis zu ihrem Tod gegeben, sondern dieser Leidensweg wird als christliches Martyrium gedeutet. Diese Martyrien seien in einer Situation der Verfolgung für den wahren Glauben erfolgt, die „heimtückischer und schwerer als alle vorhergehenden heidnischen und häretischen Verfolgungen“ sei. Sie gelte ungerechterweise „uns und Gott“. ${ }^{73}$ Um die Adressaten davon zu überzeugen, dass es sich bei den beschriebenen Leiden nicht um Folgen rechtmäßiger staatlicher Strafmaß-

70 Er nennt die Ambigua (Ambigua ad Thomam, PG 91,1032 - 1060; 1-34 JANSSENS, CCSG 48), Ambigua ad Iohannem (PG 91, 1061 -1417), die Capita theologica et oeconomica (PG 90,10841173), die Capita de caritate (PG 90, 960 - 1073; A. CERESA-GASTALDO, ed., Massimo Confessore.

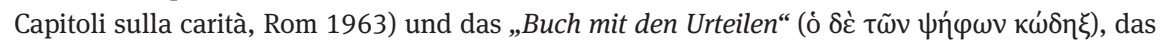
man dabei mit Schweigen übergehen könne: Contra Const. 231, 26-31 (AlLEN/NeIL). Mit Letzterem sind wahrscheinlich die Akten der Lateransynode von 649 gemeint. Bei den $\psi$ ń $\varphi$ o handelt es sich dann um die dortigen Anathematismen. Dies ist ein wichtiger Hinweis, dass die tatsächliche Autorschaft der Lateranakten unter den Anhängern des Maximos bekannt gewesen ist und auch öffentlich verbreitet wurde. Dazu s. unten S. 124-125. 146.

71 Contra Const. 231, 45 (ALLEN/NEIL).

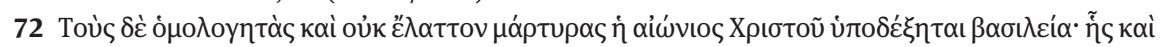

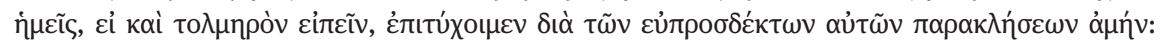
Contra Const. 232, 54-57 (ALLEN/NEIL).

73 S.oben Fußnote 37. 
nahmen handelte, sondern die Leidenden zu einem Christi Dei martyr geworden seien, wird auf das tugendhafte Ertragen des Leidens bis zum Tode verwiesen. Im Vordergrund aber stehen die Wunder vor und nach dem Tode der Verurteilten, die hier eine zentrale Funktion der Legitimation der Personen, ihres Leidens und ihres Werkes erhalten. Das Wunder dient dem Erweis der Heiligkeit der Verurteilten und der Qualifizierung ihres Leidens als Martyrium. Dazu gehört das Wunder „göttlicher Offenbarung“, durch das Maximos und auch Anastasios ${ }^{74}$ ihre Todestage vorher bekannt gewesen seien und Maximos sogar sein Martyrium „etliche Jahre zuvor“ vorhergesagt habe. Die propagierte Beweiskraft der Wunder wird der Autorität der vertretenen dyotheletischen Lehre dienstbar gemacht. Das Licht am Grabe des Maximos „bringt Klarheit“ und „macht offensichtlich“, wer er sei, nämlich ein wahrhafter Märtyrer Christi mit Parrhesia, den man nun auch anrufen kann. ${ }^{75}$ Die mit der Prothese geschriebenen Schriften des Anastasios lasse diese „mit dem Finger Gottes“ geschrieben sein; ${ }^{76}$ dies gibt ihnen eine dem Dekalog analoge Bedeutung. In allem zeige sich so die „Vorhersehung und Mitwirkung Gottes“, der „wunderbar ist in seinen Heiligen“. So kann es auch nicht mehr überraschen, dass bei den Verfassern des Hypomn. und ihren Kreisen, für die die Schmähschrift Contra Constantinopolitanos ein weiteres Zeugnis ist, bereits ein lebendiger Märtyrerkult der Verurteilten praktiziert wurde. Er schlägt sich nieder in der verwendeten Titulatur der als Märtyrer Verehrten. Theodoros ist bereits i. J. 655/56 nach Cherson gereist um das Grab Martins zu besuchen und zu verehren. Das bedeutet, dass dieser erste Schritt einer kultischen Verehrung unmittelbar nach dem Tod des Papstes und schon sechs Jahre vor der Verurteilung des Maximos und seiner Schüler einsetzte. Ep. Anast. ist in der eingangs formulierten Absicht geschrieben worden, dem „Gedächtnis der Gerechten“ (Prov 10,7 LXX) zu dienen und hat mit dem Begriff Mvń $\eta_{\text {n }}$ den Zentralbegriff der Märtyrer- und Heiligenverehrung benannt. Das Hypomn. scheint dabei bereits liturgische Verwendung gefunden zu haben. ${ }^{77}$

74 Hypomn. 205,120-125 (ALLEN/NEIL). Anastasios habe darüber hinaus bereits weitere Wunder an seinen früheren Verbannungsorten Trapezunt und Mesembria vollbracht.

75 Hypomn. 215,256-257 (AlLEN/NeIL). Dieser Terminus ist einschlägig und macht Maximos zum Inhaber jener besonderen Qualität „of martyrs, who, having $\pi .(\alpha \rho \rho \eta \sigma i \alpha)$ before their persecutors, attain to $\pi$. ( $\left.\alpha \rho \rho \eta \sigma^{\prime} \alpha\right)$ before God, so that their intercession becomes efficacious." (G.W.H. LAMPE, A Patristic Greek Lexicon. ${ }^{10}$ Oxford 1991, 1045 s.v., II A 3d). Wurde hier noch die Anrufung des hl. Maximos um Intercessio propagiert, so wird sie am Ende von Contra Const. bereits praktiziert. S. oben Fußnote 72.

76 S.oben Fußnote 46 und 50.

77 Vgl. oben Fußnote 43. 
Dieser Märtyrerkult ist von einem Märtyrerbewusstsein getragen worden, das die i. J. 662 Verurteilten bereits während ihrer ersten Verbannung nach 655 entwickelt haben. Im Hypomn. schlägt sich dies in der Nachricht nieder, Maximos habe bereits Jahre zuvor sein Martyrium vorhergesagt, sowie in der befremdlichen Information, dass sich die Verurteilen bereits zu Lebzeiten am Sammeln ihrer Kontaktreliquien aktiv beteiligt haben. Die zwischen 656 und 657 entstandenen wichtigsten Quellen zum Hochverratsprozess gegen Maximos und seine Schüler, die während des ersten Exils von Autoren, die zum direkten Umfeld des Maximos gehörten - möglicherweise sogar unter dessen Beteiligung - verfasste sog. Relatio motionis ${ }^{78}$ und die sog. Disputatio Bizyae ${ }^{79}$ dokumentieren ebenfalls bereits dieses Märtyrerbewusstsein. Es handelt dabei sich um literarische Konstruktionen, die die bewusst in Kauf genommene Strafe noch vor ihrem Vollzug als Martyrium deuten und in der Gestaltung dieser „Protokolle“ die Analogie zu frühchristlichen Märtyrerprozessen suchen. Es handelt sich um literarische Produkte der Selbstdeutung als Märtyrer. ${ }^{80}$

Dieser Märtyrerkult ist abgesehen von einem Kult an den Gräbern angesichts des Adressaten von Ep. Anast., der Verfasser des Hypomn. und der in diesem enthaltenen Informationen sowie der überwiegend palästinischen Herkunft der Mönchskreise um Maximos aller Wahrscheinlichkeit nach in Palästina/Jerusalem praktiziert worden und war wohl auch auf diese Region örtlich begrenzt. Dass in diesem Zeitraum an einen hauptstädtischen Maximoskult nicht zu denken ist, wird der nächste Abschnitt deutlich machen.

\section{Der Ort des Maximoskultes am Ende des 7. Jh.s}

Auf dem VI. Ökumenischen Konzil (680/1) ist es - wie gesagt - trotz der Rezeption wesentlicher Theologumena des maximianischen Dyotheletismus zu keiner Rehabilitierung des Maximos gekommen und deshalb auch zu keiner reichskirchlichen Rezeption seines beginnenden Märtyrerkultes. Dafür lassen sich im Wesentlichen zwei Gründe nennen. ${ }^{81}$

78 Relatio motionis inter Maximum et principes: ALLEN/NeIL (Hrsg.), Scripta (wie oben Fußnote 4) $12-51$.

79 Acta in primo exsilio seu dialogus Maximi cum Theodosio ep. Caesareae in Bithynia: ALLEN/NeIL (Hrsg.), Scripta (wie oben Fußnote 4) 72-151.

80 Vgl. dazu den Nachweis im Detail H. OHME, Maximos Homologetes (†662). Martyrium, Märtyrerbewusstsein, „Martyriumssucht“. ZAC 20 (2016), im Druck.

81 Zum Vorwurf des Origenismus als weiterem Grund s. unten S. 134. Die von P. AlLEN und B. NEIL gebotene Erklärung trifft m.E. nicht den Kern: „Maximus was not mentioned at the sixth 
1. Als erstes muss man sich klarmachen, dass die im ersten Hochverratsprozess im Jahre 655 vorgebrachten Anklagepunkte weiterhin bekannt waren und anscheinend als stichhaltig betrachtet wurden. Die provozierende Starrheit gegenüber allen kaiserlichen und kirchlichen Vermittlungsversuchen hatte Maximos wohl auch noch die letzten Sympathien geraubt.

Maximos hatte spätestens seit der arabischen Eroberung Jerusalems im Jahre 638 in Erwartung des Untergangs des Imperiums und des bevorstehenden Endgerichts $^{82}$ gelebt und ist von daher mit politischem Kalkül an einer Destabilisierung der Herrschaft des Herakleios und Konstans II. beteiligt gewesen, ${ }^{83}$ deren Religionspolitik er dafür verantwortlich gemacht hatte. So soll er dem Magister militum von Numidien, Petros Illustrios, der 633/34 den Befehl erhalten hatte, gegen die Araber zu ziehen, von diesem Feldzug abgeraten haben. Petros habe ihn als „heiligen Mann“ vorher um Rat gefragt $\mathrm{t}^{84}$ und Maximos habe brieflich geraten: „Tue das nicht, denn Gott gefällt es nicht, dem Römischen Staat unter der Herrschaft des Herakleios und seines Geschlechtes beizustehen. “85 Petros Illustrios

Ecumenical Council, probably to spare imperial embarrassment over his recent condemnation and martyrdom“: Dies., Documents (wie oben Fußnote 27) 30.

82 Vgl. dazu: H. OHмE, Die Bedeutung der Geschichtstheologie im monenergetisch-monotheletischen Streit: Zeitschrift für Theologie und Kirche 112 (2015) 27-61.

83 Dieses Ergebnis der neueren Forschungen ist m. E. nicht mehr in Frage zu stellen. Vgl. Brandes, Krisenbewältigung (wie oben Fußnote 12); DERS., Konstantin der Große (wie oben Fußnote 12); Воотн, Crisis (wie oben Fußnote 6); Jankowiak, Essai (wie oben Fußnote 6); Boudignon, Maxime le Confesseur (wie oben Fußnote 7); DERS., Le pouvoir de l'anathème (wie oben Fußnote 13). Die von J. HowaRD-Johnston jüngst wieder vertretene Deutung der hagiographischen Tradition, dass die Hochverratsanklagepunkte gegen Maximos „fadenscheinig“ und „vorgeschoben“ seien (DERS., Witnesses to a world crisis. Historians and histories of the Middle East in the seventh century. Oxford 2010, 157 -162: 160) sind angesichts dieser Forschungen m.E. nicht zu halten. Zu den Thesen von HowARD-Johnston i.e. vgl. OHME, Maximos (wie oben Fußnote 80).

84 Relatio motionis 15,33 (ALLEN/NEIL). Dies entsprach ganz der allgemeinen byzantinischen Praxis höchster Staatsfunktionäre bis hin zum Kaiser selbst, vor entscheidenden Handlungen Rat

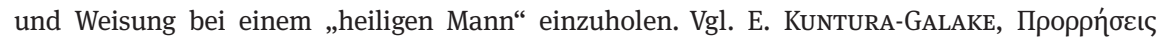

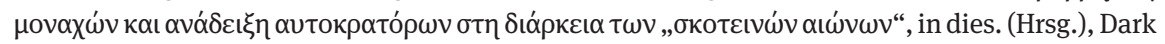
centuries (wie oben Fußnote 12) 421-441.

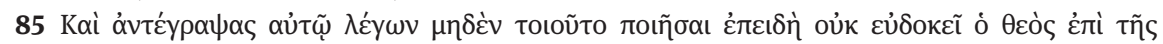

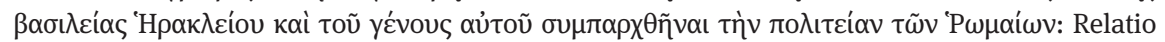
motionis 15,34-37 (Allen/NeIL). Bоoth (mit Rückgriff auf Jankowiak, Essai, wie oben Fußnote 6) hat deutlich machen können, dass seit den persischen Eroberungen die aus Palästina geflohene Mönchsgruppe um Johannes Moschos, Sophronios und Maximos mit Parteigängern in Palästina eine zunehmend distanzierte Haltung gegenüber Herakleios und seiner Herrschaft einnahm, die auch durch den Sieg über die Perser nach 628 nicht rückgängig gemacht wurde. Die Identifizierung von Imperium und Kirche wurde je länger je mehr in Frage gestellt. In diesem 
hatte daraufhin tatsächlich den Gehorsam verweigert und war nicht gegen die Araber gezogen. Dies brachte Maximos die Anklage ein: „Du allein hast Ägypten, Alexandrien, die Pentapolis, Tripolis und ganz Africa an die Sarazenen verraten!“86 Weiterhin wurde er angeklagt, den Usurpationsversuch des Exarchen von Africa, Gregorios, im Jahre 645/46 unterstützt zu haben. ${ }^{87}$ Maximos und sein Kreis haben außerdem sogar die ideologische Begründung für die Autorität des Kaisers als höchste institutionelle Verkörperung der christlich-römischen politeia auch in kirchlichen Fragen prinzipiell in Frage gestellt, indem sie den mit der Melchisedektypologie begründeten Anspruch, „Kaiser und Priester“ zu sein, rundheraus abgelehnt haben. ${ }^{88}$

Vor allem aber hatte Maximos zusammen mit der Gruppe aus Palästina geflohener Mönche und in Kooperation mit dem aus Jerusalem stammenden griechischen Papst Theodoros I. (642-649) ${ }^{89}$ die Lateransynode von 649 vorbereitet und bewusst den Weg äußerster kirchlicher Konfrontation mit der Kirche von Konstantinopel gesucht. Dieses Mönchskollektiv hat sich unter der Leitung des Abtes des palästinischen Sabas-Klosters, Johannes, durch die vorbereitete Verlesung einer eigenständigen dogmatischen Stellungnahme ${ }^{90}$ und die damit ver-

Zusammenhang spielte die rituelle Abgrenzung gegenüber den vorchalcedonensischen Kirchen und die programmatische Bekämpfung jeder Interkommunion eine hervorgehobene Rolle. Umso mehr habe sich die Abwendung von Herakleios verstärkt, als dieser im Rahmen seiner Unionspolitik von Armeniern und Severianern, ja sogar Nestorianern persönlich die Kommunion empfing.Vgl. Воотн, Crisis (wie oben Fußnote 6) 160-164. 184-185. 221. Über dieser Frage scheint es zu einer Spaltung im Patriarchat Jerusalem gekommen zu sein, vgl. ebd. 186-188. Die als Skandal betrachtete inzestuöse Ehe des Kaisers mit seiner Nichte Martina (seit 611) wird das ihre zu dieser Distanzierung beigetragen haben.

86 Relatio motionis 13, 24-26 (ALLEN/NEIL).

87 Gregorios plante anscheinend ein „orthodoxes“ Reich mit dem in Konstantinopel abgesetzten und zum Dyotheletismus „,bekehrten“ Patriarchen Pyrrhos als Patriarch. Die Durchsetzung des maximianischen Dyotheletismus auf mehreren Synoden in Africa war dazu der Anfang. Vgl. J.F. HALDON, Byzantium in the seventh century. The transformation of a culture. Cambridge ${ }^{2} 1997$, 306-307; J. L. van Dieten, Geschichte der Patriarchen von Sergios I. bis Johannes VI. (610 - 715). Amsterdam 1972, 83-85. Zur Umdeutung der Konstantin-Vision auf Gregorios in einem Traum des Maximos vgl. BRANDES, Krisenbewältigung (wie oben Fußnote 12) 185 -192; DERS., Konstantin der Große (wie oben Fußnote 12).

88 Relatio motionis 25, 182 - 27, 208 (Allen/NEIL). Vgl. dazu G. DAGRon, Emperor and priest. The imperial office in Byzantium. Cambridge 2003, 173-183; Онме, Maximos Homologetes (†662), Martyrium (wie oben Fußnote 80).

89 PmbZ Nr. 7769.

90 Es handelt sich um den sog. Libellus von 36 Mönchen - unter ihnen Maximos an 34. Stelle: ACO II 1, p.48, 25 - 57, 39 (Riedinger); R. Price / Ph. Booth / C. Cubitt, The Acts of the Lateran Synod of 649. Translated Text for Historians 61. Liverpool 2014, 150-156; WinkELMANN, Streit (wie oben Fußnote 6) Nr. 108. 
bundene Petition zum Motor der dogmatischen Positionierung der Synode und ihrer radikalen konfrontativen Haltung gemacht. Dies hatte dann tatsächlich zu einer Anathematisierung der bisherigen Konstantinopeler Patriarchen des 7. Jahrhunderts, Sergios, Pyrrhos und des regierenden Paulos, zusammen mit Theodoros von Pharan, Kyros von Alexandrien samt allen ihren Anhängern geführt, die in eine Reihe mit den Häresiarchen Sabellius, Arius, Nestorius, Eutyches u. a. gestellt wurden. ${ }^{91}$ Dazu war der gesamte Aktenbestand ${ }^{92}$ dieser Synode einschließlich der Reden der Bischöfe! - von diesen Mönchen um Maximos in Rom zuvor kompiliert und komponiert worden. ${ }^{93}$ Nach $\mathrm{CH}$. BoudignON handelt es sich hierbei um eine „Machtergreifung“ der Palästinenser unter Zustimmung des römischen Klerus als entscheidendem Schachzug einer internationalen Strategie. ${ }^{94}$ Diese Synode, für die sogar die Autorität eines ökumenischen Konzils in Anspruch genommen wurde, ${ }^{95}$ war eine reichsrechtlich illegale Veranstaltung ${ }^{96}$ und die Karikatur einer kirchlichen Synode, die deswegen auch in den Akten des VI. Ökumenischen Konzils (680/1) kein einziges Mal namentlich erwähnt wird. Aber seit dem Oktober 649 war nicht nur die Kirchengemeinschaft zwischen der römischen und der konstantinopolitanischen Kirche aufgehoben, sondern die letztere kollektiv unter das „Anathema“ des Lateranense gestellt worden mit der Folge, dass Maximos und seine Kreise auch in Konstantinopel selbst jede „communicatio in sacris“ ablehnten, wenn nicht die Beschlüsse dieser Synode ein-

91 ACO II 1, p. 378, 29 - 384, 25; 380, 5-12 (RIEDINGER).Vgl. WinkELMANn (wie oben Fußnote 6) Nr. 110.

92 Dies sind 436 Seiten bei R. Riedinger (ed.), Acta Conciliorum Oecumenicorum. Series Secunda. Volumen Primum: Concilium Lateranense a. 649 celebratum. Berlin 1984. Vgl. WinkELMANN, Streit (wie oben Fußnote 6) Nr. 110.

93 Vgl. R. RiEdinger, Kleine Schriften zu den Konzilsakten des 7. Jahrhunderts. Instrumenta Patristica, 34. Turnhout 1998. Der lateinische Text der Akten ist in wesentlichen Teilen, insbesondere den Reden, eine Übersetzung aus dem Griechischen. Dies ist heute Konsens. Die weitergehende These Riedingers, dass auch die lateinische Übersetzung vom Maximoskreis angefertigt wurde und von den Synodalen die fertigen Texte einfach vorgelesen wurden, hat sich nicht durchsetzen können. Vgl. P. Conte, Il Sinodo Lateranense dell'ottobre 649. Rom 1989; R. PRICE, General introduction, in ders., Lateran Synod (wie oben Fußnote 90) 59-68. In den maximianischen Kreisen war die Erinnerung daran auch noch am Ende des 7. Jh. anscheinend lebendig. S. oben Fußnote 70.

94 Boudignon, Pouvoir (wie oben Fußnote 13) 245-274.

95 Maximos hat die Lateransynode so bezeichnet: Opuscula theol. et polem. 11 (PG 91, 137D). Die beanspruchte Ökumenizität der Synode ergibt sich weiterhin aus der Forderung, dass die zuvor in Rom kopierten und an alle großen Kirchen verschickten Akten überall synodal rezipiert werden sollten. Vgl. dazu die Enzyklika Papst Martins I. - auch hier ist der griechische Version der Originaltext des Briefes! (ACO II 1, p.404-420: 412, 2-4. 11-12 RIEDINGER).

96 So bereits E. CASPAR, Die Lateransynode von 649. ZKG 51 (1932) 75-137: $133 \mathrm{f}$. 
schließlich der Anathematismen gegen die Patriarchen vorher anerkannt würden. Er stellt sich dazu auf den anmaßenden Standpunkt, dass die in der Hauptstadt gefeierte eucharistische Liturgie ein geistloser und damit entleerter und wirkungsloser liturgischer Ritus sei, solange dort noch die auf der Lateransynode anathematisierten Patriarchen in den Diptychen kommemoriert würden. ${ }^{97}$ Schließlich hat Maximos jede Oikonomia-Regelung in der theologischen Streitfrage prinzipiell abgelehnt ${ }^{98}$ und jeden Versuch einer Überwindung des Schismas und einer theologischen Verständigung zu unterlaufen versucht. ${ }^{99}$

2. Zum anderen ist der 681 synodal rezipierte maximianische Dyotheletismus im byzantinischen Episkopat keinesfalls ohne weiteres mehrheitsfähig gewesen. Dies lässt sich in mehrfacher Hinsicht verdeutlichen. So zeigt bereits der Verlauf des VI. Ökumenischen Konzils, mit welchen Schwierigkeiten die Durchführung von dessen Beschlüssen verbunden gewesen ist. Denn die römischen Legaten bestanden im Gefolge der Lateransynode auch 681 auf der Anathematisierung von inzwischen nicht weniger als vier Konstantinopler Patriarchen und der ca. fünfzigjährigen kaiserlichen Religionspolitik. G. DE GREGORIO und O. KRESTEN haben dargelegt, dass die Sitzungen XII-XVII dieser Synode von der kaiserlichen Konzilsregie in hinhaltender Absicht eingeschoben worden waren und damit ca. sechs Monate gebraucht wurden, um hinter den Kulissen in Gegenwart Kaiser Konstantins IV. (668-685) diese höchst schwierige Frage der Anathematismen zu klären. Als man sich dann geeinigt hatte, wurde eine 17. Sitzung als Generalprobe oder Probeschlusssitzung durchgeführt, um zu prüfen, ob auch alle Bischöfe tatsächlich unterschreiben würden, oder ob sich unter den Synodalen gegen diese Zumutung für die Kirche von Konstantinopel Widerstand regen würde. ${ }^{100}$

Der Sohn Konstantins IV., Justinian II. (685-695, 705-711), ${ }^{101}$ hat offensichtlich aus ähnlichen Gründen - gleich nachdem er im Juli 685 infolge des frühen Todes seines Vaters im Alter von 16 Jahren den Thron bestiegen hatte Ende 686 oder Anfang 687 eine Reichsversammlung zur Bestätigung der Beschlüsse und der kaiserlichen Inobhutnahme der Akten des VI. Konzils durch-

97 Relatio motionis 31, 249 - 33, 264 (ALLEN/NEIL); Disputatio Bizyae 81, 83-85; 113, 434-436 (Allen/Neil). Vgl. dazu OHme, Maximos (wie oben Fußnote 80).

98 Vgl. OHмE, Oikonomia (wie oben Fußnote 6) 308-343. 337-343.

99 Vgl. Оhмe, Maximos (wie oben Fußnote 80).

100 G. De Gregorio / O. Kresten, Il Papiro conciliare P. Vindob. G. 3: Un ,Originale’ sulla via da Constantinopoli a Ravenna (e a Vienna), in L. Pani / C. Scalon (eds.), Le Alpi porta d'Europa. Scritture, uomini, idee da Giustiniano al Barbarossa. Atti del Convegno internazionale di studio dell' Associazione italiana dei Paleografi e Diplomatisti (Cividale del Friuli 5.-7.10.2006). Spoleto 2009, 233-379. 276-279. 287-292. Der Papyrus Vindobonensis Graecus 3 ist der Restbestand der Subskriptionsliste der 17. Sitzung des VI. Konzils.

101 PmbZ Nr. 3556. 
geführt. ${ }^{102}$ Er hat bei dieser Gelegenheit den von seinem Vater wohl wegen Widerstandes gegen dessen Konzilspläne i.J. 679 abgesetzten, von ihm selbst aber wieder in sein Amt eingesetzten Patriarchen Theodoros I. (677-679, 686-687) ${ }^{103}$ zusammen mit den wichtigsten Vertretern von Staat, Militär und Kirche die Akten des VI. Konzils unterschreiben lassen, darunter 130 Bischöfen. ${ }^{104}$ Daraus ist m.E. der Schluss zu ziehen, dass eine synodale Durchsetzung des Dyotheletismus und eine zusätzliche Rehabilitation seines Hauptvertreters, der wegen Hochverrats verurteilt worden war und wesentlich für die Anathematisierungspolitik der Lateransynode verantwortlich war, im Jahre 681 und auch noch später aus politischen und kirchenpolitischen Gründen gar nicht in Frage kam.

Diese prekäre Lage für die Rezeption des VI. Ökumenischen Konzils im byzantinischen Episkopat wird auch noch bei dem ebenfalls von Justinian II. einberufenen Concilium Quinisextum (691/92) deutlich, denn mit seinem grundlegenden can. 1 war es zuerst auch eine weitere Bestätigung der Gültigkeit des VI. Ökumenischen Konzils. Es kann kein Zufall sein, dass die Reichsversammlung von 686/87 in diesem Kanon eigens erwähnt wird. ${ }^{105}$ Dass eine wirkliche Rezeption des VI. Konzils immer noch ausstand, wurde nach dem endgültigen Sturz Justinians II. im Jahre 711 nochmals deutlich, als der Usurpator Philippikos Bardanes (Nov. 711-Juni 713) ${ }^{106}$ als eine seiner ersten Amtshandlungen auf einer Synode im Jahre 712 das von Justinian II. in persönliche Obhut genommene kaiserliche Exemplar der Konzilsakten verbrennen ließ und das III. Constantinopolitanum außer Kraft setzte - unter Beteiligung auch solch späterer „Leuchten der Orthodoxie“ wie

102 F. DöLGER / A.E. MÜLLER, Regesten der Kaiserurkunden des oströmischen Reiches. I, 1. Regesten 565-867, 2. Aufl. besorgt u. Mitarbeit v. J. PReiSer-Kapeller / A. Riehle von A.E. MÜLlER. München 2009, Nr. 256a; ACO ser. II, 2, 2 p. 886, 3 - 887, 21 (RiEdingeR). Vgl. dazu vaN Dieten,Geschichte (wie oben Fußnote 87) 146-148; De Gregorio/ Kresten, Papiro (wie oben Fußnote 100) $322-333$.

103 PmbZ Nr. 7954; van Dieten (wie oben Fußnote 87) 125-129. 146-148.

104 Vgl. K.-H.Uthemann, Die dem Anastasios Sinaites zugeschriebene Synopsis de haeresibus et synodis. Einführung und Edition. Annuarium Historiae Conciliorum 14 (1982) 58-94: §26 (86, 17-23).

105 Es heißt dort, dass das VI. Konzil „auf bedeutendere Weise Rechtskraft empfing, weil der fromme Kaiser (sc. Justinian II.) dessen Akten zu ihrer Sicherheit in alle Ewigkeit mit Siegeln

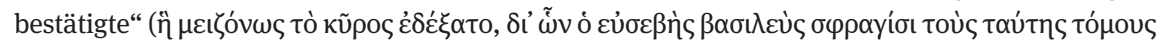

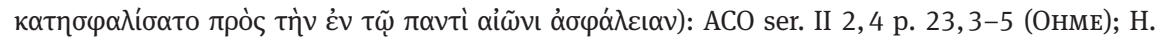
Онме, Concilium Quinisextum - Das Konzil Quinisextum. Fontes Christiani, 82. Turnhout 2006, 176, 4-6.

106 PmbZ Nr. 6150. 
des Metropoliten und nachmaligen Ökumenischen Patriarchen Germanos von Kyzikos und des Metropoliten Andreas von Kreta! ${ }^{107}$

In diesem Zusammenhang ist es bedeutsam, dass es dasselbe Quinisextum gewesen ist, das die von Maximos propagierte prinzipielle Infragestellung des kaiserlichen Selbstverständnisses als „Kaiser und Priester“ hinsichtlich der damit verbundenen liturgischen Sonderrechte des Kaisers auf kirchenrechtlicher Ebene zurückgewiesen hat. So hat diese Synode in can. 69 zwar den Laien das Betreten des Altarraumes verboten, den Kaiser aber davon ausdrücklich mit folgenden Worten ausgenommen: „Keineswegs soll aber die kaiserliche Majestät und Autorität daran gehindert werden, wenn sie dem Schöpfer Gaben darbringen möchte, gemäß sehr alter Tradition“. 108

Eine Märtyrer- und Heiligenverehrung des Maximos und seiner Schüler ist deshalb nach 681 vor allem auf Kreise außerhalb des Reiches, insbesondere im palästinischen Mönchtum, beschränkt gewesen. Aber auch hier kann nicht von einer umfassenden Rezeption des Kultes gesprochen werden. Dies wird im Werk des Sinaimönches und Abtes Anastasios Sinaites (ca. 610 - nach 701) deutlich. ${ }^{109}$ Denn in dessen authentischem Werk spielen Person und Werk des Maximos noch keine nennenswerte Rolle! Für das Hauptwerk des Sinaiten, den Hodegos, lässt sich dies mit dem Herausgeber, K.-H. UthemanN, folgendermaßen erklären: „Die einzelnen Teile des Hodegos seit der Zeit des Cyrus von Alexandrien bis spätestens 686/7 (sind) vermutlich [...] noch vor dem 6. Ökumenischen Konzil entstanden [...] und zwischen 686 und 689 zu einem ,Gesamtwerk' zusammengestellt worden“, ohne dass sich im Text ein Hinweis auf das VI. Ökumenische Konzil oder die gesamte monenergetisch-monotheletische Kontroverse findet. Dies liege daran, dass „der Verfasser eine Widerlegung des Monophysitismus beabsichtigte und sich deshalb nicht mit ,innerkirchlichen' Fragen der chalkedonischen Kirche auseinandersetzen wollte. “ ${ }^{110}$ In seiner im Jahre 701 entstandenen sog. 3. Homilie

107 Theophanes, Chronographia 381, 20-23; 382, 6-21 (DE BooR). Vgl. Winkelmann, Streit (wie oben Fußnote 6) Nr. 177. 180. 180c. De Gregorio/Kresten, Papiro (wie oben Fußnote 100) 331f. mit Anm. 273 gehen auf der Grundlage des Berichtes des Chartophylax Agathon von einem consistorium aus. Zu Andreas vgl. PmbZ Nr. 362; zu Germanos PmbZ Nr. 2298.

108 ACO ser. II 2, 4 p. 50 (Онме); OHмE, Concilium Quinisextum (wie oben Fußnote 105) 118. 260.

109 PmbZ Nr. 268; Zu Anastasios K.-H. UthemanN, Anastasios Sinaites. Byzantinisches Christentum in den ersten Jahrzehnten unter arabischer Herrschaft. Arbeiten zur Kirchengeschichte, 125. Berlin/Boston 2015.

110 K.-H. Uthemann, Anastasii Sinaitae viae dux. CCSG, 8. Turnhout 1981, Einleitung CCXVIII mit Anm. 72. 
über die Erschaffung des Menschen ${ }^{111}$ bietet Anastasios Sinaites zwar eine detaillierte, allerdings fehlerhafte, jedoch wirkmächtige Kurzfassung des monenergetisch-monotheletischen Streites, in der es ihm vor allem um eine geschichtstheologische Deutung der Ereignisse jener Zeit ging. ${ }^{112}$ So interpretiert er dort die Verbannung Papst Martins und die Amputationsstrafen an Maximos und seinen Schülern in geschichtstheologischer Perspektive ganz auf das darauf folgende Strafhandeln Gottes hin. Die Namen des Maximos und seiner Schüler aber hält er dabei keiner Erwähnung wert, ${ }^{113}$ und Sophronios von Jerusalem kommt in seiner Darstellung überhaupt nicht vor! Es handelt sich hier um ein deutliches Indiz gegen einen Maximoskult im Umfeld des Sinaiten.

Dies steht allerdings in starkem Kontrast zu der hervorgehobenen Würdigung des Maximos und Sophronios in der Anastasios zugeschriebenen Synopsis de haeresibus et synodis. ${ }^{114}$ Denn jener Teil der Synopsis, der dem monotheletischen Streit und dem VI. Konzil gewidmet ist (§§ 17-26), verrät „detaillierte Kenntnisse, die in einem eigentümlichen Kontrast zur dürftigen und recht ungenauen Darstellung des Monotheletismus im sog. Sermo III“ des Sinaiten aus dem Jahre 701 stehen. ${ }^{115}$ Dort werden nicht nur Papst Martin und die Lateransynode erwähnt (§ 20), sondern ausführlich die Bedeutung des Sophronios in der Auseinandersetzung mit Kyros von Alexandrien und Patriarch Sergios von Konstantinopel ge-

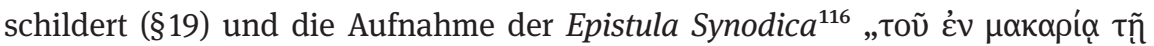

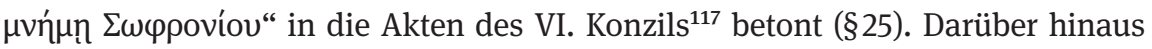
werden ausführlich Person und Werk und Schicksal des Maximos - unter Betonung seines Mönchstandes ${ }^{118}$ und Erwähnung seiner beiden Schüler Anastasios Monachos und Anastasios Apokrisiarios - geschildert (§21). Dabei trägt die Darstellung des Leidensweges von Papst Martin und der verstümmelt nach Lazike Exilierten hier nun hagiographischen Charakter:

111 Sermo adv. Monotheletas qui communiter dicitur Homilia tertia de creatione hominis, ed. K.-H. Uthemann (55-83, CCSG 12); CPG 7749; WinkelmanN, Streit (wie oben Fußnote 6) Nr. 175. 112 Anast. S., serm. imag. 3, 1 (84-101 Uthemann, CCSG 12). Vgl. dazu van Dieten, Geschichte (wie oben Fußnote 87) Exkurs II, 179-218; OHME, Geschichtstheologie (wie oben Fußnote 82) 33-35. 55-61.

113 Anast. S., serm. imag. 3, 1 (59, 84 - 61, 101 Uthemann, CCSG 12).

114 Uthemann, Synopsis (wie oben Fußnote 104).

115 Ebd. 68-69.

116 P. AlLEN, Sophronius of Jerusalem and seventh-century heresy. The Synodical Letter and other documents. Oxford 2009.

117 ACO ser. II, 2, 2 p. 410, 13 - 494, 8 (RIEDINGER).

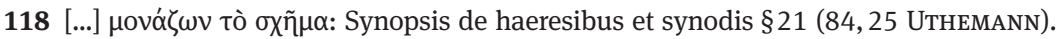




\begin{abstract}
„Deswegen (sc. wegen der Lateransynode) wird er aus der Stadt Rom fortgeschleppt und nach Byzanz gebracht, und indem der Vollkommen-Apostolische den Kampf zur Unsterblichkeit durchkämpfte ( $\delta \iota \theta \lambda \eta \dot{\sigma} \sigma \alpha)$, wurde er für immer zur Verbannung verurteilt, in welcher er das

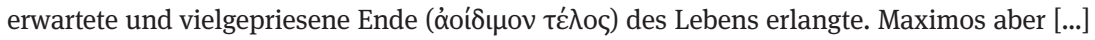
empfängt zusammen mit seinen beiden Schülern, den Anastasioi, das Erbe Martins, würdig der Erkenntnis und der Tat nach. Meinte man, dass es dem Augenschein nach sinnlos sei zu sterben, so gaben sie doch ihre Seelen sowie das irdische Leben in die Hand Gottes. Maximos übertraf alle, deren Gedenken jemals wegen ihrer Geisteskraft fortlebt; er schmückte das Leben mit (seinem) Leben - dies nämlich ist die kämpferische Erkenntnis! Als sie (sc. die Gegner) Anstalten machten, sie in vielfältiger Weise durch Angst, Schmeichelei und Versprechungen abzubringen (sc. von ihren Überzeugungen), setzten sie sich doch keineswegs durch. Vielmehr hielten sich jene davon fern und ließen die Wellen sich wie an einem Stein brechen. Die Gottlosen schnitten die Zunge ab und amputierten Hand und Füße (sic!) und

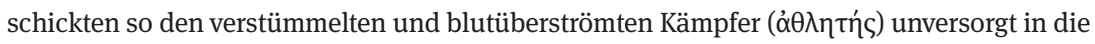
Region Lazike. Einen jeden der Schüler exilierten sie an einen anderen Ort. In gleicher Weise wie der Lehrer bestraft, trennten die von ruchloser Gesinnung Beherrschten sie, den einen dem Stand nach Presbyter, den anderen richteten sie durch schwerste Misshandlungen übel zu." 119
\end{abstract}

Deutlich steht hier das persönliche Schicksal und die Bewährung der Verurteilten im Zentrum des Interesses. K.-H. UTHEMANN hat wegen dieser Diskrepanz zu den erstgenannten Werken des Sinaiten die Konsequenz gezogen, dass die §§1-14 der Synopsis „Anastasios Sinaites selbst nicht abgesprochen werden können“120, mit den $§ \S 17-26$ aber „ein anderer Autor, der offenbar Zeitgenosse des Sinaiten war“ in der jetzt vorliegenden Fassung des monotheletischen Streites und des VI. Konzils die entsprechenden Kapitel des Anastasios verdrängt habe. ${ }^{121}$ Dies muss zwischen 686/87 und 691/92 erfolgt sein, denn die Synopsis bricht nach der Erwähnung des VI. Konzils und der o.g. Reichsversammlung Justinans II. ab, ohne das Concilium Quinisextum von 691/2 noch zu erwähnen. Trotz aller hagiographischen Anklänge und auch Übertreibungen ${ }^{122}$ werden den gepriesenen Kämpfern für die Wahrheit hier aber die entsprechenden Titulaturen öyıs oder öбıৎ noch nicht verliehen! Das bedeutet, dass ca. drei Jahrzehnte nach dem Tode der Genannten in der Überarbeitung der Synopsis Indizien für eine beginnende Heiligenverehrung vorliegen, die sich allerdings mit der öffentlichen Vergabe der Titulaturen noch zurückhält. Der Überarbeiter hatte Zugang zu der Schrift des Sinaiabtes und korrigierte diese unter Betonung des Mönchsstandes und des Je-

119 Synopsis de haeresibus et synodis $\S \S 20-21$ (84, 21-39 UTHEMANN), Übersetzung H. Ohme.

120 Uthemann, Synopsis (wie oben Fußnote 104) 72.

121 Ebd. 72 -73. Genauso jetzt Uthemann, Anastasios Sinaites (wie oben Fußnote 109) 779781.

122 Die Füße wurden den Verurteilten bekanntlich nicht amputiert. 
rusalemer Beitrages zur Überwindung des Monenergismus-Monotheletismus. Man wird schließen dürfen, dass dies in den bislang deutlich gewordenen Zirkeln der palästinischen Anhängerschaft des Maximos erfolgte.

\section{Maximos und sein Kult in der Epoche des Ikonoklasmus}

Der Mönch Theophanes Confessor (759/60 - 818), ${ }^{123}$ dessen Chronographia den Zeitraum von 284-813 abdeckt, prädiziert dort im Rahmen seiner Informationen zum monenergetisch-monotheletischen Streit Papst Martin I. und Maximos mehrfach als „Heilige“ und „Bekenner““ ${ }^{124}$ Dennoch ist er über wichtige Details der Propagandaliteratur für eine kultische Verehrung beider nicht im Bilde. Die zeitlichen Angaben sind - wie häufig in der Chronographia - durchweg unpräzise.

Bereits in der von Theophanes unter AM 6121 (AD 628/29) gebotenen vorausschauenden Darstellung des Streites bis zur römischen Synode des Jahres 680 unter Papst Agatho (678-681) ${ }^{125}$ bezeichnet er Maximos und Martin als

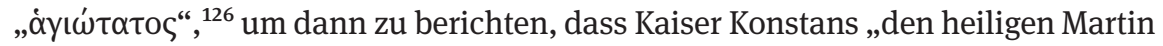

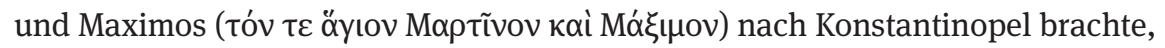
sie folterte und nach Cherson und in die Klimata ins Exil verbannte. “127 Mit $\tau \dot{\alpha}$ к $\lambda i_{\mu}^{\prime} \mu \alpha \alpha$ ist der südliche Teil der Krim gemeint. ${ }^{128}$ Offensichtlich ist Theophanes der Ort der letzten Verbannung des Maximos und seines Todes unbekannt gewesen. Unter AM 6149 (AD 656/57) berichtet er, dass in diesem Jahr ,gegen den heiligen Maximos und seine Schüler“ vorgegangen wurde, „die für den rechten Glauben gegen die Monotheleten gekämpft hatten“.

Weil Konstans nicht vermochte, sie zu seiner Irrlehre hinüberzuziehen, schnitt er die gott-

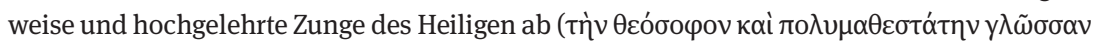

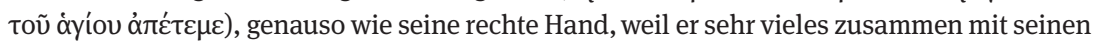
Schülern, den Anastasii, gegen dessen Gottlosigkeit verfasst hatte, was diese auch in Dia-

$123 \mathrm{PmbZ}$ Nr. 8107; HowARD-JohnSTON (wie oben Fußnote 83) 268-312.

124 Papst Martin wird unter AM 6150 (AD 657/8) als ò Chronographia 347, 21-23 (DE BooR). Zu Maximos s.unten.

125 PmbZ Nr. 129

126 Theophanes, Chronographia 331, 12. 25 (DE BOoR). Beim Papst könnte es sich auch um eine Titulatur handeln, bei Maximos indes nicht.

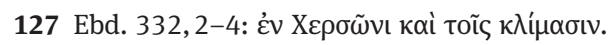

128 C. MAngo / R. Scott, The Chronicle of Theophanes Confessor. Oxford 1997, 463 Anm. 16.

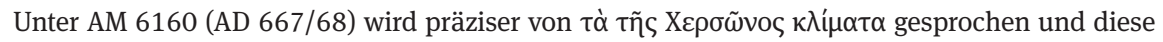
Angabe korrekt nur auf Martin bezogen (351,19 DE BooR). 


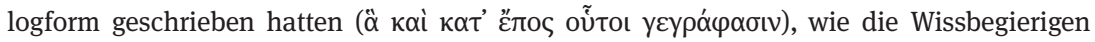
wissen. $^{129}$

Theophanes zieht hier also den 1. und 2. Prozess gegen Maximos zusammen und berichtet an dieser Stelle nur die Verstümmelung des Maximos. Die Schlusswendung haben C. MANGo und R. ScotT wohl zu Recht auf die in Dialogform verfasste Relatio motionis und die Disputatio Bizyae bezogen. ${ }^{130}$ Man könnte in dieser Formulierung einen Hinweis auf die Beteiligung des Maximos an der Abfassung dieser Texte erblicken. Unter AM 6160 (AD 667/68) erwähnt Theophanes dann die Ermordung Kaiser Konstans' II. in Syrakus und gibt als Grund an, dass der Kaiser einerseits „,von den Byzantinern“ wegen der Ermordung seines Bruders gehasst worden sei,

besonders aber, weil er den hochheiligen römischen Papst ehrlos nach Konstantinopel gebracht und in die Klimata von Cherson exiliert hatte, und weil er Maximos, dem hochweisen

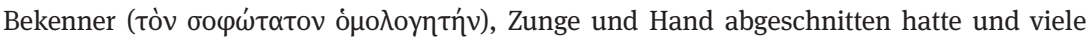
Orthodoxe zu Misshandlungen, Exil und Enteignung verurteilte, weil sie sich nicht zu seiner Häresie überreden ließen, und die beiden Anastasii, die Schüler des Bekenners und Märtyrers

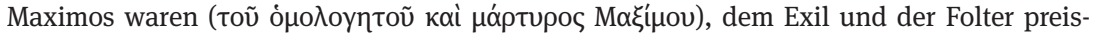
gab. ${ }^{131}$

Anastasios Monachos und Anastasios Apokrisarios werden von Theophanes also nicht als Heilige, Bekenner oder Märtyrer bezeichnet. „Bekenner“ sind Martin und Maximos, nur dieser aber auch Märtyrer. Damit ist die Person des Maximos deutlich herausgehoben aus der Gruppe der 655/62 Verurteilten. Theophanes sieht in deren Leidensweg einen wesentlichen Grund für die Ermordung des Kaisers.

Theophanes lebte und wirkte in Konstantinopel und war Bilderfreund. Er verweigerte sich der ikonoklastischen Reaktion unter Kaiser Leon V. $(813-820)^{132}$ und wurde wegen seines Festhaltens an der Ikonenverehrung und den Beschlüssen des II. Nicaenums von 787 nach 815 festgenommen und nach Samothrake exiliert. Den geschilderten Darstellungen in seiner Chronographia wird man entnehmen können, dass ihm seit Ende des 8. Jh.s eine entsprechende kultische Verehrung des Maximos nicht unbekannt gewesen sein wird, obwohl er den Ort

129 Theophanes, Chronographia 347, 7-14 (DE BOoR).

130 MAngo/Scott, Chronicle (wie oben Fußnote 128) 484 Anm. 3. M.E. sollte man hier auch die Disputatio cum Pyrrho hinzunehmen, die wohl ebenfalls erst in der Zeit zwischen 655-662 entstanden ist.Vgl. J. NoRET, La rédaction de la Disputatio cum Pyrrho (CPG 7698) de Saint Maxime le Confesseur serait-elle postérieure à 655? Analecta Bollandiana 117 (1999) 291-296.

131 Theophanes, Chronographia 351,17-24 (DE BOoR).

132 PmbZ Nr. 4244. 
seines Todes nicht kennt. Auf einen in Konstantinopel verbreiteten oder gar offiziell anerkannten Kult in diesem Zeitraum wird man daraus m. E. aber nicht schließen können. Fragen könnte man, ob die dargestellten Urteile bereits Teil der von Theophanes kompilierten Quellen gewesen sind. Was davon identifizierbar ist, ${ }^{133}$ kommt hierfür jedenfalls nicht in Frage, so dass man in den Bekenner-, Märtyrer- und Heiligkeitstitulaturen für Maximos und Papst Martin I. wohl ein Urteil des Theophanes und seiner ikonodulen zelotischen Mönchskreise erblicken muss. Es hat nach diesen ersten Beobachtungen zur Epoche des Bilderstreites den Anschein, dass der Maximos-Kult in Konstantinopel zu dieser Zeit in ikonodulen monastischen Kreisen zu suchen ist, die im Hintergrund der hier festgestellten Indizien einer Heiligenverehrung stehen. Die weiteren Texte werden dies bestätigen.

Patriarch Nikephoros (757/8 - 828; sedit 806-815) ${ }^{134}$ stammte aus einer ikonodulen Familie und hatte als kaiserlicher Asekretis am VII. Ökumenischen Konzil im Jahre 787 teilgenommen. Als Patriarch wurde er wegen des Umschwungs in der Bilderfrage unter Leon V. im Jahre 815 abgesetzt und verbannt. ${ }^{135}$ Seine dann im Exil entstandenen Werke zur Verteidigung der Ikonen sind allerdings für unsere Fragestellung wenig ergiebig. Das aus den 70er Jahren stammende historiographische Frühwerk, ${ }^{136}$ das den Zeitraum 602-769 behandelt, enthält für die Regierungszeit Konstans II. (641-668) eine merkwürdige Lücke, über deren Ursachen man nur spekulieren kann. Die einzige Erwähnung des Maximos im Breviarium des Patriarchen erfolgt in Kap. 31, wo „Maximos und Theodosios“ im Kontext der Disputatio cum Pyrrho vom Jahre 645 als Anführer der Mönche in Africa erwähnt werden. ${ }^{137}$ Die Namensnennung ist erstaunlich distanziert und enthält keinerlei Hinweise auf eine Verehrung des Maximos. Erst in dem nach 820 geschriebenen Spätwerk des Nikephoros, der Refutatio et eversio definitionis synodalis anni 815, die weitgehend aus einer Zusammenstellung älterer Texte des

133 Vgl. MAngo/Scott, The Chronicle (wie oben Fußnote 128) LXXIV-LXXXI.

134 PmbZ Nr. 5301.

135 Zum Konflikt vgl. Th. Pratsch, Theodoros Studites (759-826) - zwischen Dogma und Pragma. Berliner Byzantinistische Studien, 4. Frankfurt/M. 1998, $203-231$.

136 Nikephoros, Patriarch of Constantinople: Short History. Text, translation and commentary by C. MANGo. CFHB, 13. Washington D.C. 1990. Vgl. dazu HowaRd-Johnston, Witnesses (wie oben Fußnote 83) 237-267.

137 Nikeph. Patr., Brev. 31, 33 (MANGo). In Kap. 37 über das VI. Ökumenische Konzil erfolgt keine Erwähnung des Maximos. 
Autors besteht, ${ }^{138}$ tauchen Anzeichen einer Verehrung des Maximos auf, wenn der Patriarch ein Zitat des Maximos aus den Ambigua einführt mit der Bemerkung:

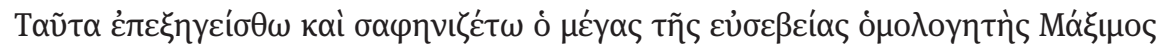

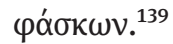

Bei dem Zeitgenossen beider Vorgenannten, dem Reformer des koinobitischen Mönchtums und Abt des Studiosklosters Theodoros Studites $(759-826),{ }^{140}$ wird ein Maximoskult an einigen wenigen Stellen deutlicher, auch wenn in den 560 erhaltenen Briefen des Studiten Maximos nur ein einziges Mal erwähnt wird. In ep. 471, einem Schreiben an einen Schüler namens Gregorios aus den Jahren 821$825,{ }^{141}$ fordert Theodor diesen auf, dem Metropoliten von Chalkedon mitzuteilen, dass die vom „heiligen Maximos“ vertretene Lehre von drei Arten der Apokatastasis auf Gregor von Nyssa und den Apostel Paulus zurückgehe. Mitnichten sei origenistisch, was „der Vater Maximos“ sage. ${ }^{142}$ Neben der Titulierung des Maximos als Heiliger macht der kurze Brief deutlich, dass der Vorwurf des Origenismus gegen Maximos auch in den zwanziger Jahren des 9. Jh.s noch immer im Raume stand. Maximos hatte sich während des Prozesses i.J. 655 durch eine Verfluchung des Origenes selbst vor dem Vorwurf des Origenismus schützen müssen. ${ }^{143}$ Man wird hierin einen weiteren Grund erblicken dürfen, der der offiziellen Rezeption eines in bestimmten Kreisen gepflegten Maximos-Kultes entgegenstand.

Ein weitaus gewichtigerer Grund ergibt sich aber aus folgender Beobachtung. In seinem antikonoklastischen Antirrheticus II benutzt Theodoros als Traditionsbeweis für den Bilderkult ein Zitat aus der Disputatio Bizyae. ${ }^{144}$ Es handelt sich um jene Passage am Ende des ersten Gespräches in Bizye am 24. August 656, bei dem es zu einer scheinbaren Einigung zwischen Maximos und Bischof Theodosios von Kaisareia gekommen war, woraufhin alle zu einem Dankgebet niederknieten und zur Bestätigung des Gesagten das Evangelium, das Kreuz, eine Christus- und eine Marienikone küssten und mit den Händen berührten. ${ }^{145}$ Diese Textpassage ist

138 J. M. Featherstone (HrsG.), Nicephori Patriarchae Constantinopolitani refutatio et eversio definitionis synodalis anni 815. Refutatio et eversio definitionis synodalis anni 815. CCSG, 33. Turnhout 1997, XVII.

139 Ebd. Kap. 50, 1 f. (96 Featherstone).

$140 \mathrm{PmbZ}$ Nr. 7574. Pratsch, Theodoros Studites (wie oben Fußnote 135).

141 G. Fatouros, Prolegomena, in ders., Theodori Studitae Epistulae. CFHB, 31. Berlin / New York, I 433*, II 676-678.

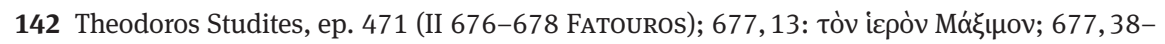

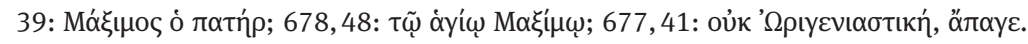

143 Relatio motionis 29, 225 - 230 (ALLEN/NEIL).

$144 P G$ 99, 381AB.

145 Disputatio Bizyae 462-467 (117 AlLEn/NeIL); vgl. ebd. 648-651 (133 AlLEN/NeIL). 
in der Tat ein wichtiges Zeugnis für eine in der Mitte des 7. Jh.s praktizierte Proskynese von Ikonen. ${ }^{146}$ Deshalb hatte das VII. Ökumenische Konzil diese Stelle bereits als Testimonium in seinen Traditionsbeweis aufgenommen und zur Feststellung der Authentizität des Textes aus verschiedenen $\beta$ í $\beta \lambda$ o zweimal verlesen

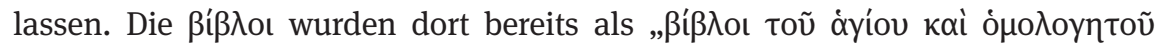

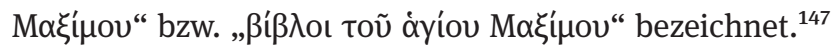

Das bedeutet, dass Maximos während des Bilderstreites von ikonoduler Seite $\mathrm{zu}$ einem namhaften Zeugen der Ikonenverehrung erhoben und in diesem Zusammenhang als Heiliger und Bekenner tituliert wurde. Es ist m. E. bemerkenswert, dass der Studite diese Stelle ohne Erwähnung des II. Nicaenums zitiert,

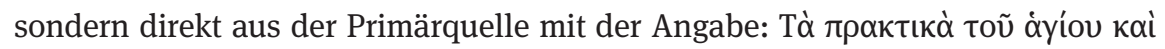

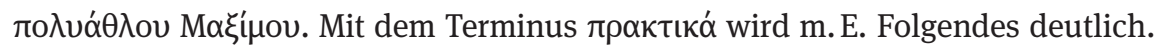
Innerhalb der gesammelten Werke des Maximos, die den Bilderverehrern 787 in Nicaea als $\beta$ í $\beta$ 入o vorlagen, galten die Disputatio Bizyae zusammen mit der Relatio motionis - beide werden in den Handschriften stets zusammen überliefert! - in ikonodulen Kreisen als Prozessakten des Maximosprozesses mit Protokollcharakter. Damit wurde der tendenzöse Charakter dieser literarischen Produkte des Maximos-Kreises und die damit verbundenen Deutung des erwarteten Urteils als Martyrium ${ }^{148}$ von den Ikonenverehrern rezipiert, so dass im Zusammenhang eines hier existierenden Maximoskultes diese Texte anscheinend als Märtyrerakten galten.

Der Ursprung dieser Tradition und der damit verbundenen Instrumentalisierung des Maximos im Bilderstreit liegt allerdings wiederum in Jerusalem/Palästina. Denn zuvor war es bereits Johannes von Damaskos († vor 754) ${ }^{149}$ gewesen, der in seinem zweiten Logos ,gegen diejenigen, die die hl. Ikonen verleugnen“ und dann auch im dritten unter den am Ende aufgeführten Chreseis für die Ikonenverehrung eben diese Passage aus der Disputatio Bizyae aufgenommen hatte. ${ }^{150}$

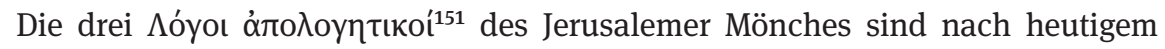

146 Für die Annahme einer Interpolation dieser Stelle, wie BRANDES, Anmerkungen (wie oben Fußnote 19) 176 mit Anm. 43 vermutete, besteht m. E. kein Anlass.

147 ACO ser. II 3, 2 p. 340,9 -342, 19 (LAMBERz). In actio VI hat die Synode diese Stelle im Kontext der Widerlegung des Horos von Hiereia erneut aufgenommen, vgl. Mansi XIII, 362 D9-E2. 148 Vgl. dazu im Detail Oнмe, Maximos (wie oben Fußnote 80).

149 PmbZ, Nr. 2969.

150 Imag. II 65 (B. KotTER, Hrsg., Die Schriften des Johannes von Damaskos, Band 3: Contra imaginum calumniatores orationes tres. PTS, 17. Berlin / New York 1975, 164); Imag. III 131 (ebd. 196).

151 KotTER ebd. 
Konsens nicht vor Ende der vierziger Jahre des 8. Jh.s anzusetzen. ${ }^{152}$ Das bedeutet, dass zu diesem Zeitpunkt in Jerusalem jene Texte so gut bekannt waren, dass eine eigentlich nebensächliche Passage dem aktuellem Anlass des Bilderstreites unmittelbar dienstbar gemacht werden konnte. In Imag. II 65 wird Maximos in der

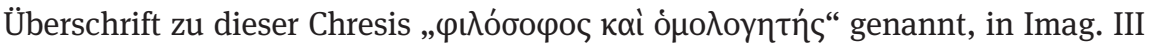
131 wird er als $\alpha \beta \beta \alpha \varsigma$ bezeichnet und das Zitat dann mit der Wendung eingeführt:

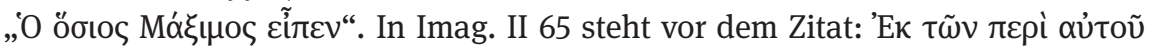

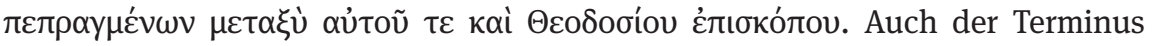
$\pi \varepsilon \pi \rho \alpha \mu \varepsilon \dot{v} \alpha$ macht deutlich, dass bereits hier die Quelle dieses Testimoniums mit einem weiteren technischen Begriff für Prozessprotokolle bezeichnet wurde und damit der Anspruch der Texte, Märtyrerakten zu sein, übernommen wurde.

Überdies hat der Damaszener nun in jeder der drei Reden ${ }^{153}$ gegen kaiserliche Maßnahmen und Gesetze in der Bilderfrage mit Worten und Argumenten polemisiert, die die Polemik des Maximos gegen den Anspruch, „Kaiser und Priester“ zu sein, übernehmen und aktualisieren. ${ }^{154}$ „John of Damascus does little more than repeat [...] the complains of Maximus the Confessor." 155 Auch sonst erweist er sich als Kenner der Werke des Maximos, findet sich in der Expositio fidei doch eine Fülle von - allerdings dem Programm entsprechend nicht kenntlich gemachten Zitaten des „Confessors“. ${ }^{156}$

Zusammenfassend lässt sich Folgendes sagen: Anscheinend hat das Aufkommen einer lehrmäßig abgesicherten ikonoklastischen Religionspolitik im byzantinischen Reich in den vierziger Jahren des 8. Jh.s und die Erhebung der

152 Traditionell wurden die Logoi früh nach 726 und 730 datiert. Vgl. H.-G. ThüMmEL, Die Konzilien zur Bilderfrage im 8. und 9. Jahrhundert. Das 7. Ökumenische Konzil in Nikaia 787, Paderborn u. a. 2005, 46f. 54. Es mehren sich jedoch die Stimmen, die im 1. Logos eine Antwort auf die Peuseis Konstantins V. und den zweiten Logos in Erwartung der bevorstehenden Synode von Hiereia geschrieben sehen und von daher zu einer späteren Datierung gelangen. Vgl. P. SPECK, Artabasdos, der rechtgläubige Vorkämpfer der göttlichen Lehren. Poikila Byzantina, 2. Bonn 1981, 179-243; DeRs., Bild und Bilderstreit in Byzanz, in M. Brandt / A. Effenberger, Die Macht der Bilder. Katalog, Hildesheim 1998, 56-67; L. BRUBAKER / J. F. HALDON, Byzantium in the Iconoclast Era ca. 680 - 850: a history. Cambridge 2011, 120. 183-187.

153 Imag. I 66; II 16. 69; III 12 (166-167; 112-114; 102-104 КотTER).

154 Vgl. z. B.: „Ich akzeptiere keinen Kaiser, der das Priestertum auf tyrannische Weise an sich reißt!“: Imag. II 16 (113, 66 - 114, 68 KOTTER).

155 DAGRon, Emperor (wie oben Fußnote 88) 184.

156 Vgl. B. KotTer, (Hrsg.), Die Schriften des Johannes von Damaskos. Bd. 2. Expositio fidei. PTS, 12. Berlin / New York 1973, Indizes, 256-257. Es handelt sich um direkte und modifizierte Textübernahmen aus den Opuscula theologica et polemica und der Disputatio cum Pyrrho. 
bilderfeindlichen Theologie zum Reichsdogma auf der Synode von Hiereia (754) ${ }^{157}$ einen Aktualisierungsschub für die in einigen Kreisen bereits bestehende Heiligen- und Märtyrerverehrung der beiden Hauptprotagonisten des monenergetischmonotheletischen Streites, Maximos und Papst Martin I., zur Folge gehabt. Deren Autorität als Märtyrer der Orthodoxie sollte bei den Bilderfreunden nun auch gegen die jetzt aufkommende und als Häresie bewerte bilderfeindliche Theologie ins Feld geführt werden. Damit aber war die Person des Maximos erneut Bestandteil eines bedeutenden kirchenpolitischen Konfliktes im byzantinischen Reich geworden. Wiederum stand der Name des Maximos in Opposition zur kaiserlichen Religionspolitik. Überdies kam die Initiative zu diesem Heiligenkult zusammen mit dem Widerstand gegen die bilderfeindliche Religionspolitik auch noch von außerhalb des Reiches. Einer offiziellen byzantinischen Rehabilitierung des Maximos standen damit zusätzliche Hindernisse im Wege.

In diesem Zusammenhang verdienen auch noch die beiden sog. Briefe ${ }^{158}$ Papst Gregorius' II. $(715-731)^{159}$ an Kaiser Leon III. (717-741) ${ }^{160}$ Erwähnung, weil sie detaillierte Kenntnisse der Texte zu den Prozessen gegen Papst Martin I. und Maximos verraten.

Die Authentizität dieser Briefe ist bekanntlich mehr als hundert Jahre kontrovers diskutiert worden. ${ }^{161}$ Nach der Untersuchung und Edition von J. GouILLARD $^{162}$ sowie den Analysen von P. SPECK ${ }^{163}$ und H. MICHELS ${ }^{164}$ ist ein breiter Konsens über die Unechtheit beider Briefe festzustellen. Die in einem äußerst scharfen, ja geradezu unverschämten Ton und unter Missachtung aller formalen Normen päpstlicher Briefe dieses Zeitraums geschriebenen Texte stehen schon

157 Vgl. Die ikonoklastische Synode von Hiereia 754. Einleitung, Text, Übersetzung und Kommentar ihres Horos, besorgt v. Th. KRANNich / CH. SCHUberT / C. SodE. Studien und Texte zu Antike und Christentum, 15. Tübingen 2000.

158 Ph. Jaffé, Regesta pontificum Romanorum ad a.p.Chr.n. MCXCVIII. ${ }^{2}$ Leipzig 1881-1888 (ND Graz 1956), Nr. 2180. 2182.

159 PmbZ Nr. 2522.

160 PmbZ Nr. 4242.

161 Den Diskussionsverlauf bis 1988 dokumentiert H. MicheLs, Zur Echtheit der Briefe Papst Gregors II. an Kaiser Leon III. ZKG 99 (1988) 376-391; zum gegenwärtigen Stand vgl. DöLGER/ MÜLLER, Regesten (wie oben Fußnote 102), Reg. 280 g (279).

162 J. Gouillard, Aux origines de l'Iconoclasme: le témoignage de Grégoire II? TM 3 (1968) 243 307; Edition 277 - 297, 299-305. Eine auszugsweise (tendenziöse) deutsche Übersetzung findet sich bei H. RaHnER, Kirche und Staat im frühen Christentum. München 1961, 438-459.

163 P. SPECK, Ich bin's nicht, Kaiser Konstantin ist es gewesen. Die Legenden vom Einfluß des

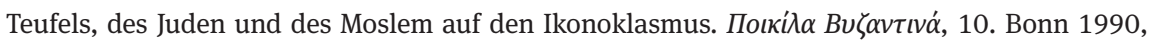
637-695.

164 Michels, Echtheit (wie oben Fußnote 161). 
durch ihre Behauptung radikaler bilderstürmerischer Maßnahmen ${ }^{165}$ Leons III. im Widerspruch zur feststellbaren bilderfeindlichen Politik dieses Kaisers, so dass sie für dessen Regierungszeit als Quellen nicht herangezogen werden können. ${ }^{166}$ Ihre Entstehung ist vielmehr im byzantinischen Osten zu lokalisieren und muss vor 814 erfolgt sein, werden sie doch von Theophanes als „vielen gut bekannt“ erwähnt, der sie allerdings dem Jahre 724/5 zuordnet. ${ }^{167}$

Besondere Aufmerksamkeit hat diesen Texten auch G. DAGRON geschenkt. ${ }^{168}$ Denn im Zentrum der dort behaupteten Polemik des Papstes gegen den Kaiser steht dessen angebliche Aussage „Ich bin Kaiser und Priester!“169 als Begründung für seine Maßnahmen. Der Autor dieser Texte betont demgegenüber die Unabhängigkeit der Bischöfe in allen kirchlichen Angelegenheiten, aus denen sich die Kaiser herauszuhalten hätten, zumal sie im liturgischen Sinne keinerlei priesterliche Funktionen in Anspruch nehmen dürften. ${ }^{170}$ DAGRON hat weiterhin wichtige Beobachtungen zum Entstehungsmilieu gemacht: „It was a milieu with an active memory extending back to about 650 . The historical allusions that stud the two texts are rare and cursory for the earlier periods, but numerous and significant when they relate to the arrest and deportation of Pope Martin, the martyrdom of Maximus the Confessor. “171 Der Autor sei überdies bemerkenswert vertraut mit zentralen Texten dieses Konflikts. Neben dem Hypomnesticon ist es die Relatio motionis, deren Absage ${ }^{172}$ an das kaiserliche Selbstverständnis als „Kaiser und Priester“ geradezu als Quelle für den Schreiber der Gregorius-Briefe betrachtet werden müsse. ${ }^{173}$

Tatsächlich wird Leon III. Kaiser Konstantin IV. (668-685) als vorbildlicher Kaiser entgegengehalten, habe dieser doch auf dem VI. Ökumenischen Konzil nicht den Vorsitz in Anspruch genommen und sei sogar bereit gewesen, seinen eigenen Vater Konstans zu anathematisieren. ${ }^{174}$ Weiterhin wird Leon die Drohung in den Mund gelegt, er werde den Papst in Rom gefangennehmen lassen, „wie es

165 Vgl. ep. 1, 22 - 25. 199 (279, 293 GouILlaRd).

166 „They are of no relevance to the actual history of the period (sc. Leos' III) dealt with here“: Brubaker/HALdon, Byzantium (wie oben Fußnote 152) 83 Anm. 52.

167 Theophanes, Chronographia AM 6217; 6221 (404,6-9; 408,28-29 DE BooR); MANGo/ ScotT, Chronicle (wie oben Fußnote 128) 558. 565.

168 DAGRon, Emperor (wie oben Fußnote 88) 158-166..

169 Ep. 2, 293 (299 GouILlARD).

170 Ep. 1,192-195 (291-293 GouILlaRd); ep. 2, 316-333 (301 GouIllaRd).

171 DAGRon, Emperor (wie oben Fußnote 88) 166.

172 S. dazu oben Fußnote 88.

173 DAGRON, Emperor (wie oben Fußnote 88) 167-171.

174 Ep. 1, 186-191 (291 GouILLARD); ep. 2, 294-301 (299 GouILLARD). Davon kann natürlich keine Rede sein. 
einst Konstans mit Martin gemacht hat"“. ${ }^{175}$ Gregor entgegnet hier, dass er dann rechtzeitig fliehen werde; es werde ihm deshalb nicht so ergehen wie seinem Vorgänger Martin, den Konstans tyrannisch nach Byzanz hatte entführen lassen.

Und er tat ihm viele Bösartigkeiten an und schickte ihn ins Exil. Aber auch dem Mönch Maximos und dessen Schüler Anastasios erwies er viele Bosheiten und schickte sie ins Exil nach Lazike [...] Vom seligen Martin aber legt die Stadt, in die er verbannt wurde, Cherson und Bosporos und der ganze Norden Zeugnis ab, und die Bewohner des Nordens strömen zu seinem Grab zusammen und empfangen dort Heilung. ${ }^{176}$

Diese sog. Briefe Papst Gregors II. an Leon III. bestätigen also die bisherigen Beobachtungen, wonach das Gedächtnis der in den Prozessen von 653/55 und 662 Verurteilten besonders in ikonodulen Kreisen gepflegt wurde. Für den Autor steht hier verständlicherweise das Schicksal Papst Martins im Vordergrund. Denn die Intention dieser Texte bestand darin, ein analoges Eingreifen des Papsttums wie im monotheletischen Streit so im gegenwärtigen Konflikt zu befördern. So lässt der Autor den Papst sogar ausrufen: „Ach, würdest du doch auch uns würdigen, den Weg Martins zu beschreiten!“177 Ausdrücklich wird zwar ebenfalls Maximos und sogar Anastasios Monachos erwähnt. Auffällig ist allerdings, dass nur der Papst als „Seliger“ bezeichnet wird und nur die Wunder an seinem Grab Erwähnung finden. Maximos aber ist schlicht nur Mönch. M. E. hängt dieser Unterschied auch mit der Frage der Datierung dieser Texte zusammen.

J. GouILlard hat die Entstehung dieser Texte „dans la période militante de l'iconoclasme“ angesetzt und in Konstantinopel oder dessen Umgebung lokalisiert. ${ }^{178}$ P. SPECK hat den Kern der Briefe ähnlich als gegen Konstantin V. gerichtet betrachtet, dann aber mehrere Redaktionen postuliert, in deren Gefolge Gregor II. schließlich zum Absender geriet, was erst nach 800 erfolgt sei. Bei der Frage der Datierung wurde folgender Passage bislang keine Aufmerksamkeit geschenkt, in der Gregor den Kaiser zitiert, der geschrieben habe: „Warum wurde denn auf den sechs ökumenischen Konzilien nie über Bilder gesprochen?“ Darauf antwortet der

175 Ep. 1,236-238 (295 Gouillard).

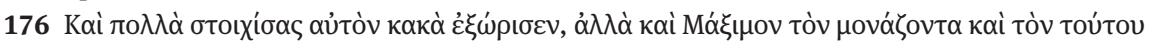

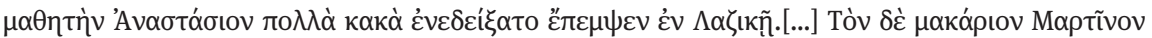

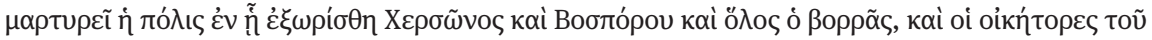

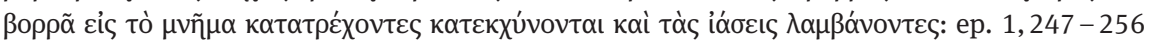
(295 Gouillard). Nach Notitia I, 62. 63 und Notitia II 66. 67 sind Cherson und Bosporos zwei autokephale Bistümer von Zekchia (Krim). Vgl. J. DARRouzÈs, Notitiae Episcopatuum Ecclesiae Constantinopolitanae. Paris 1981, 206. 218.

177 Ep. 1, 257 (297 GouIlLARD).

178 Gouillard, Origines (wie oben Fußnote 162) 275. 
Papst: „Ganz richtig, Kaiser. Es wurde dort (aber auch) nicht über Brot und Wasser geredet, essen und nicht essen, trinken und nicht trinken“, weil eben die Bilder von Anfang an Teil der Tradition gewesen seien. ${ }^{179}$ Diese fiktive päpstliche Antwort bestätigt implizit, dass die Aussage Leons zutrifft. Der Text bietet damit ein tatsächlich von ikonoklastischer Seite benutztes Argument gegen die Bilder, das allerdings voraussetzt, dass die Kanones des Concilium Quinisextum und dessen Bilderkanon can. $82^{180}$ nicht als Bestandteil des VI. Ökumenischen Konzils angesehen wurden. Dies ist in der Tat im 8. Jh. ein zentraler Streitpunkt zwischen Bilderfeinden und Bilderverteidigern gewesen, der sich in der handschriftlichen Überlieferung der Akten des Concilium Quinisextum niederschlägt. ${ }^{181}$ Mindestens mit dem II. Nicaenum aber hat sich in ikonodulen Kreisen die Bezeichnung der Kanones des Quinisextums als Kanones des VI. Ökumenischen Konzils breit durchgesetzt. ${ }^{182}$ Insofern wäre bei Entstehung des Textes nach 787 die Behauptung des Kaisers sicher nicht unwidersprochen geblieben, zumal auch Papst Hadrian I. $(772-795)^{183}$ in seinem Schreiben an Patriarch Tarasios, das auf der 2. Sitzung des VII. Konzils verlesen wurde, diese Zuordnung von can. 82 des Quinisextums zum VI. Ökumenischen Konzil bestätigt. ${ }^{184}$ M. E. muss der Text deshalb deutlich vor 787 entstanden sein. In dieser Datierung könnte auch eine Erklärung für die tituläre Zurückhaltung gegenüber dem „Mönch Maximos“ liegen. War dieser doch neben den gewiss noch bekannten Anklagepunkten von 655 durch die Aufnahme als Testimonium in die Kampfschriften des Johannes von Damaskos erneut Teil einer polarisierenden Kontroverse geworden. Eine solche Zurückhaltung gegenüber Maximos wäre bei einer Jerusalemer Provenienz der Briefe gewiss nicht zu erwarten, so dass auch von daher vieles dafür spricht, dass sie in Konstantinopel entstanden sind. Dies wird durch eine letzte Beobachtung bestätigt.

Während Johannes von Damaskos die maximianische Polemik gegen das kaiserliche Selbstverständnis als „Kaiser und Priester“ außerhalb des byzantini-

179 Ep. 2,370-374 (305 GouILLARD).

180 In diesem Kanon findet sich erstmals die Argumentation, dass das Bild Christi wegen seiner Inkarnation geradezu notwendig sei. Der Kanon bemängelt, dass ,,auf manchen Abbildungen der verehrungswürdigen Ikonen“ nach Joh 1,29. 36 Johannes der Täufer mit einem Lamm dargestellt wird. Ab sofort solle die Darstellung des Menschgewordenen an die Stelle des Lammes treten: ACO ser. II 2, 4 p. 54 (Онме); Онме, Concilium Quinisextum (wie oben Fußnote 105) 106-107.

181 Vgl. dazu H. OHмe (Hrsg.) Concilium Constantinopolitanum a. 691/2 in Trullo habitum (Concilium Quinisextum). ACO, ser. II 2, 4. Berlin 2013, Einleitung, LXIII-LXX.

182 Vgl. dazu H. OHмE, Das Quinisextum auf dem VII. Ökumenischen Konzil. AHC 20 (1988) $325-344$.

183 PmbZ Nr. 2536.

184 ACO ser. II 3,1 p. 174-186. 176, 7 -9 (LAmberz); dazu OHme, Concilium (wie oben Fußnote 181), Einleitung LXXXII. 
schen Reiches ungebremst weiterführte, macht schon der zweite sog. Brief Papst Gregors II. an Leon III. deutlich, wie innerhalb des byzantinischen Reiches auch bei den Anhängern des Maximos deutlich vorsichtiger agiert wurde. Obwohl die Gregorbriefe vor keinem Vorwurf gegen den Kaiser zurückschrecken, wird eine prinzipielle Unvereinbarkeit von kaiserlichem und priesterlichem Amt hier nicht mehr behauptet. Vielmehr vertritt der zweite Brief eine harmonische Verbindung beider Größen als „in Tat und Wort“ bestehende Möglichkeit, die bei etlichen Kaisern musterhaft gegeben war. ${ }^{185}$ So kann der Verfasser Leon III. in diesem Sinne - jetzt sogar mit der Titulatur ápxıрєús (!) - geradezu auffordern: „Werde Priester und Kaiser, wie du geschrieben hast!“"186

Diese Beobachtungen zu mehreren Vertretern des ikonodulen Widerstandes in der ersten und zweiten Phase des Bilderstreites machen deutlich, dass der Maximoskult in diesem Zeitraum anscheinend auch in hauptstädtischen ikonodulen Kreisen gepflegt wurde. V.M. ZHIvov hat überdies darauf hingewiesen, ${ }^{187}$ dass die Übertragung des von Maximos in der Mystagogia und in Amb. 7 entwickelten liturgischen Bildbegriffs auf die Ikone für die Entwicklung der Ikonentheologie von Johannes von Damaskos bis zu Theodoros Studites von Bedeutung gewesen sei. Diese bildertheologische Rezeption des Maximos durch die Verteidiger der Bilder zusätzlich zur Benutzung der Disputatio Bizyae als Testimonium für den Bilderkult und der Relatio motionis als Quelle ikonoduler Polemik gegen das kaiserliche Selbstverständnis als „Kaiser und Priester“ werden die hauptsächlichen Gründe gewesen sein, dass ein offizieller Maximoskult in Konstantinopel im Zeitraum des Ikonoklasmus undenkbar war.

\section{Der Maximoskult im 9. und 10. Jh.}

Schon länger wurde gesehen, dass die beiden sog. Briefe Papst Gregors II. an Leon III. nach dem Ende des Bilderstreites (843) in liturgische Sammlungen Eingang fanden, wo sie als Lesungen - im Gottesdienst oder in der Trapeza des Klosters zum Sonntag der Orthodoxie vorgesehen waren. ${ }^{188}$ Damit war anscheinend nach der endgültigen Durchsetzung des Bilderkultes in Konstantinopel ein Hindernis für eine öffentliche Praktizierung eines Kultes Papst Martins und Maximos' be-

185 Ep. 2, 294-301 (299 GouILlARD). Genannt werden: „Konstantin der Große, Theodosios der Große, Valentinianos der Große (?), Justinian der Große und Konstantin IV.“

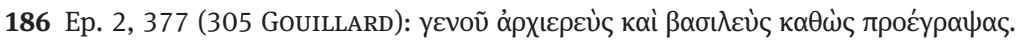

187 V.M. ZHIvov, The Mystagogia of Maximus the Confessor and the development of the Byzantine theory of the image. St. Vladimir's Theological Quarterly 31 (1987) 349-376.

188 Gouillard, Origines (wie oben Fußnote 162) 254 mit Anm. 56. 
seitigt. Allerdings wird man bedenken müssen, dass noch die antiphotianische Synode von 869/70 in can. 3 die Ikonenverehrung zur Pflicht erklären musste und für deren - offensichtlich vorkommende - Verweigerung die Exkommunikation androhte. ${ }^{189}$ Die sich nach 843 fortsetzende Spaltung der Kirche von Konstantinopel in konkurrierende kirchenpolitische Strömungen, die sich teilweise als programmatisch bestimmte „Parteien“ identifizieren lassen („Zeloten/Rigoristen“ gegen „Liberale“) ${ }^{190}$ und die im sog. „Photianischen Schisma“ zur offenen Konfrontation führte, bot für eine offizielle Rezeption des Maximoskultes anscheinend weiterhin keine guten Voraussetzungen.

So kann es dann auch nicht überraschen, wenn das kurz nach 887 entstandene Synodicon vetus keine Anzeichen eines Maximoskultes deutlich werden lässt. Und dies obwohl dessen Kapitel 128-146 über den Monotheletismus starke Parallelen $\mathrm{zu}$ Theophanes aufweisen und von denselben Quellen abzuhängen scheinen. ${ }^{191}$ Jedenfalls wird Maximos hier im Kontext der Disputatio cum Pyrrho

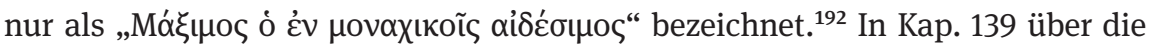
Lateransynode ist die Bezeichnung Martins als „ó óyı

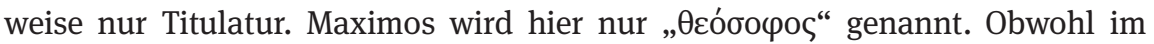
selben Kapitel auch die Prozesse und die Strafen erwähnt werden, erhalten weder Papst Martin I. noch Maximos das Prädikat „Confessor“ oder gar „Heiliger“. Maximos ist nur „der edle Maximos“. ${ }^{193}$

Das Kontrastprogramm dazu bietet eine jüngst erstmals edierte, bislang unbekannte Konzilssynopse, die etwa zeitgleich mit dem Synodicon vetus in Konstantinopel entstanden ist. ${ }^{194}$ Sie bietet in Kapitel XVI „eine in sich geschlossene ,Geschichte des Monotheletismus' [...], die so zwar sonst nicht überliefert ist, sich

189 Mansi XVI, 400C2-D5.

190 B. ZielKe, Methodios I., in: R.-J. Lilie (HRSG.), Die Patriarchen der ikonoklastischen Zeit (Berliner Byzantinistische Studien 5), Frankfurt a.M. 1999, 183-260. 230-259; F. DvoRNIK, The Photian Schism. History and Legend, Cambridge (1948) ND 1970, 37-51.

191 Vgl. van Dieten (wie oben Fußnote 87), Exkurs II, 179-218.

192 Synodicon vetus 138 (114 DUfFy/PARKER).

193 Synodicon vetus 139, 2.8 (116 DufFY/PARKER): tòv yevvoĩov [...] Máłıนov.

194 L.M. Hoffmann/W. Brandes, Eine unbekannte Konzilsynopse aus dem Ende des 9. Jahrhunderts. Forschungen zur byzantinischen Rechtsgeschichte, 30. Frankfurt/M. 2013, 21. 25 - 30. Den Autoren war nicht bekannt, dass die Kanones des Quinisextums in dieser Zeit im Osten sicher als Kanones des VI. Konzils gerechnet werden. Weil das Concilium Quinisextum nicht gesondert erwähnt wird, ziehen sie daraus die unzutreffende Schlussfolgerung, dass der Autor „eine Kanonessammlung ohne die Kanones des Quinisextum vor sich hatte“ (24. 291). Vor diesem Fehlurteil hätte schon der Text der Synopse bewahren können, der zum VII. Konzil dessen Horos zitiert, in dem can. 82 des Quinisextums vollständig zitiert und als Kanon des „sechsten heiligen und ökumenischen Konzils“ eingeführt wird (ebd. 198, 138-151). 
jedoch in eine Reihe von ähnlichen Texten einreiht, die nach dem Constantinopolitanum III von 680/681 entstanden“ sind. ${ }^{195}$ Hier ist es „der Bekenner Maximos, der in Wissen und Tugend die höchste Stufe erklommen (hat)“, der den orthodoxen Glauben verkündete und die Häresie der Monotheleten widerlegte. ${ }^{196}$ Zum Prozess von 662 weiß der Autor zu berichten:

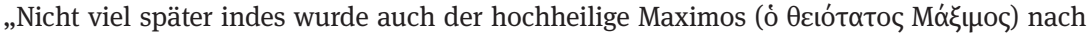
zahlreichen Verbannungen und Kämpfen wie auch Bestrafungen um der Frömmigkeit willen von demselben Kaiser in die Hauptstadt vorgeladen, und nachdem seine rechte Hand abgeschlagen und seine gottverkündende Zunge herausgeschnitten war, wurde er zusammen mit seinen Schülern in das alleräußerste Grenzgebiet der Romania verbannt. Und dort wurde

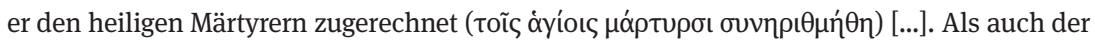

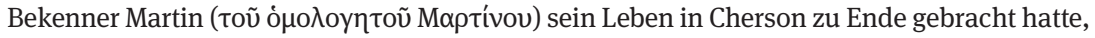
wurde der heilige Agatho zum Bischof von Rom ernannt““. ${ }^{197}$
\end{abstract}

Beide zeitgleichen Konzilssynopsen dokumentieren somit einen sehr unterschiedlichen Umgang mit der Bewertung des Schicksals von Papst Martin und Maximos noch in den 70er und 80er Jahren des 9. Jh.s in Konstantinopel. Offensichtlich ist der Maximoskult noch immer nicht offiziell rezipiert worden. Dies muss nicht überraschen, wenn man sich Folgendes klar macht.

Es charakterisiert den Weg der „Heiligsprechung“ im Bereich den orthodoxen Kirchen bis heute, dass eine zu Lebzeiten bereits verehrte Person nach ihrem Tod von ihren Anhängern als heiligmäßig kultisch verehrt wird, ein solcher Kult damit zuerst nur partikular und auch lokal praktiziert wird und erst in einem längeren Prozess kirchlich synodal rezipiert wird, um so offiziellen Status zu erlangen. ${ }^{198}$ Eine solche zuerst nur partikulare und lokale kultische Verehrung kann aber auch auf Ablehnung bei anderen Gläubigen stoßen, ja sogar zu Konflikten mit der Kirchenleitung führen, die dann die kultische Verehrung als solche zu unterbinden versucht. Dies lässt sich z. B. am Fall Symeons des „Neuen Theologen“ (9491022) ${ }^{199}$ studieren, der als Abt des Konstantinopler Mamasklosters für seinen geistlichen Vater, den Studios-Mönch Symeon Eulabes, umgehend nach dessen Tod (986/7) einen Heiligenkult eingeführt hat, der auf beträchtlichen Widerstand stieß und $\mathrm{zu}$ einem Prozess gegen Symeon führte. Dieser Kult war also nicht

195 Ebd. 32. 283.

196 Ebd.168, 26-29.

197 Ebd. 172, $67-73$.

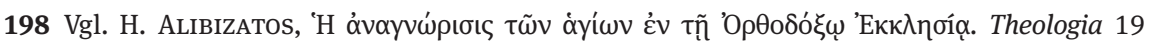

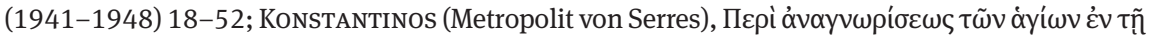

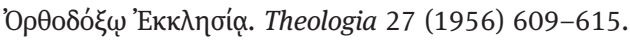

199 PmbZ Nr. 27488. 
kirchlich anerkannt, wurde gleichwohl aber praktiziert. ${ }^{200}$ Niketas Stethatos († vor 1092) ${ }^{201}$ berichtet in seiner Vita ${ }^{202}$ des Symeon Neos Theologos, was dieser im 10. Jh. unternahm, um einen Kult des Symeon Eulabes zu initiieren. Er machte die „guten Taten“ und das „apostolische Leben“ des Verehrten sowie die „Werke

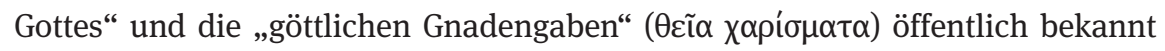

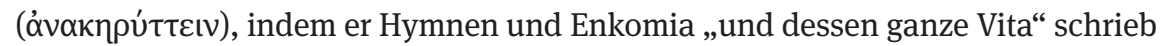

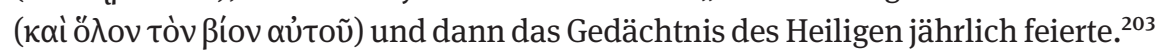
Bereits im Hypomnesticon ist uns ein sehr früher Text begegnet, der diesen Angaben entspricht und sogar eine liturgische Rubrik enthält. ${ }^{204}$ Die Epistula Anastasii Apocrisarii ad Theodosium Gangrensem versteht sich als Enkomion. ${ }^{205}$ Was wir bislang nicht in den Blick genommen haben, ist aber eine Vita mit der Passio des Maximos. Es spricht aber alles dafür, dass angesichts des in Kapitel I deutlich gewordenen frühen Maximoskultes in Palästina/Jerusalem lange vor der im 10. Jh. entstandenen griechischen Vita Maximi (BHG 1234) bereits früh auch ein Bios des Maximos existiert haben wird.

In Aufnahme einer Hypothese von W. LACKNER ist der bereits eingangs erwähnte ${ }^{206}$ Herausgeber der noch ausstehende Edition der verschiedenen hagiographischen Varianten einer Vita/Passio Maximi in Menologien, Synaxarien u.a.m., B. Roosen, zu dem Ergebnis gekommen, dass am Anfang der gesamten hagiographischen Tradition eine nicht mehr erhaltene „Urpassio“ gestanden haben müsse, die noch vor der überlieferten epitomierten Vita Maximi eines Menologiums des 9./10 Jh.s anzusetzen sei (sog. Compendium Vindobonense) ${ }^{207}$

200 Vgl. dazu J. KodER, Normale Mönche und Enthusiasten: Der Fall des Symeon Neos Theologos, in D. Simon (Hrsg.), Religiöse Devianz. Untersuchungen zu sozialen, rechtlichen und theologischen Reaktionen auf religiöse Abweichung im westlichen und östlichen Mittelalter. Frankfurt/M. 1990, 97-119.

201 PmbZ Nr. 25842.

202 I. HAUSHERR/G.Horn, Un grand mystique byzantin. Vie de Syméon le nouveau théologien (949-1022) par Nicétas Stéthatos. Orientalia Christiana, 12/1. Rom 1928.

203 Vita Symeon. N.Theol., Kap. 72, 18-20 (98 HAUSHERR).

204 S.oben Fußnote 77.

205 S. oben S. 114.

206 S. oben S. 112.

207 Roosen, Vitae (wie oben Fußnote 7) 421-426. Neben den eingangs erwähnten Zeugnissen (s. oben S. 11-112) eines offiziell installierten Maximoskultes im 10. Jh. gehören zu diesen hagiographischen Texten außerdem noch: ein Synaxarium im Codex Patmiacus 266 (s. XI-XII), das

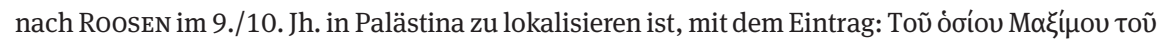

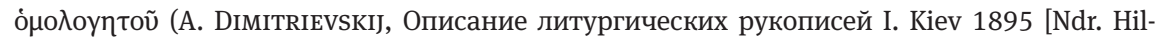
desheim 1965], 103; vgl RoosEn, Vitae, wie oben Fußnote 7, 420-421). Die Handschrift bietet den Anfang einer Passio und bezeugt einen von Konstantinopel unabhängigen Maximoskult auch durch einen doppelten Synaxareintrag am 13. und am 26. August. Weiterhin existieren noch zwei 
Wegen textlicher Parallelen dieses Compendium Vindobonense, der Passio im Synaxarium des Codex Patmensis 266 (s. XI-XII) und der Passio im Synaxarium Constantinopolitanum (s. X) mit der griechischen Vita Papst Martins (BHG 2259) zieht Roosen den m.E. überzeugenden Schluss, dass die postulierte „Urpassio“ des Maximos im zeitlichen und geographischen Umfeld der Entstehung der griechischen Vita Martins anzusetzen und auch denselben Kreisen zuzuordnen sei. ${ }^{208}$ Dabei sei mit P. CoNTE ${ }^{209}$ an Jerusalem/Palästina $z u$ denken, „a region, where the innerchalcedonian tensions between dyothelites and the emerging monothelite Maronite church continued long after the sixth Oecumenical Council“. ${ }^{210}$ Der Zeitraum sei „roughly speaking the first half of the eighth century“. ${ }^{211}$

Dieses Ergebnis wird wesentlich durch folgende Beobachtung bestätigt. Die von P. PeEters im Jahre 1933 nach dem Codex Patmiacus 254 erstmals edierte griechische Vita Martini $p p .^{212}$, die das älteste Zeugnis eines wesentlichen Be-

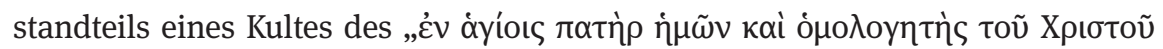
Mарті̃vo૬“ ist, ${ }^{213}$ ist ihrerseits von der maximianisch überarbeiten Fassung der oben erwähnten Synopsis de haeresibus et synodis des Anastasios Sinaites ab-

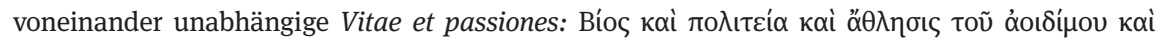

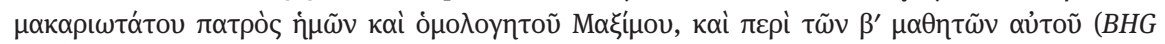

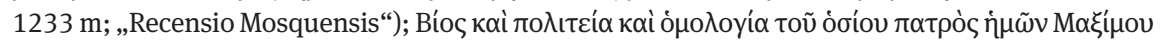
(BHG 1233n; „Recensio Atheniensis“; vgl. Roosen, Vitae, wie oben Fußnote 7, 443-451). Diese sind durch eine gemeinsame Vorlage verbunden, die ihrerseits der griechischen Vita (BHG 1234) als Vorlage gedient hat. Beide setzen Theophanes Confessor voraus und sind zwischen dem Beginn des 9. Jh. und der Mitte des 10. Jh. entstanden. Schließlich ist die Epitome einer Passio

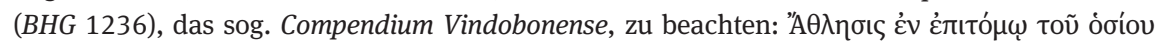

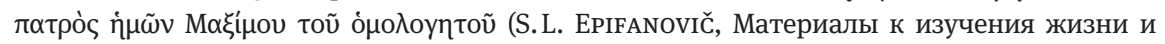
творений преп. Максима Исповедника. Kiev 1917; vgl. Roosen, Vitae, wie oben Fußnote 7, 421-423 mit Anm. 54). Sie gehört ins 9./10. Jh. zu einem Menologium mit Eintrag am 13. August.

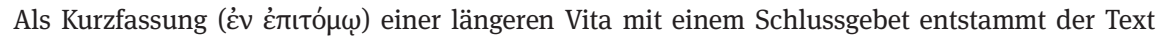
liturgischer Verwendung. BHG $1233 \mathrm{mn}$ und 1236 lassen sich geographisch nicht eindeutig zuordnen.

208 Roosen, Vitae (wie oben Fußnote 7) 427 - 433.

209 P. Conte, Il sinodo Lateranense dell'ottobre 649. La nuova edizione degli Atti a cura di Rudolf Riedinger. Rassegna critica di fonti die secoli II-XII. Vaticano 1989, 235 - 249 („12. ,Vita‘ Graeca di Martino").

210 Roosen, Vitae (wie oben Fußnote 7) 432 mit Anm. 89.

211 Ebd. 427-433. 432.

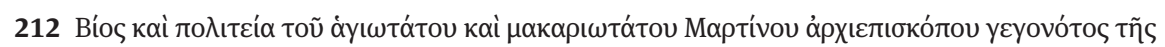

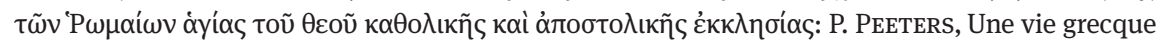
du pape S. Martin I. Analecta Bollandiana 51 (1933) 225- 262.

213 Ebd. 253, § 1, Z.1. 
hängig. ${ }^{214}$ In $\S 1$ und $\S 2$ wird die Rolle der östlichen Äbte und Mönche auf der Lateransynode von 649 stark hervorgehoben. So heißt es von Maximos - hier nun

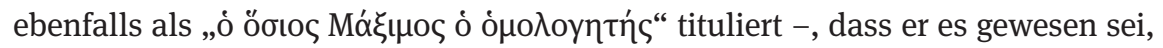
der den „hochheiligen römischen Papst Martin“ „veranlasst“/,zugerüstet“ habe ( $\alpha \rho \alpha \sigma \kappa \varepsilon v \alpha ́ \zeta \varepsilon ı)$, die Lateransynode einzuberufen und die Anathemata auszusprechen. ${ }^{215}$ Auf der Synode seien ,die Bischöfe und die Äbte und Mönche aus dem ganzen Osten aufgetreten und belehrten durch Schriften und mündliche Mitteilung über die äußerst frevelhafte Häresie““.216 Überdies wird auch noch ein Auszug aus dem Libellus ${ }^{217}$ des Bischofs Stephanos von Dora zitiert ${ }^{218}$, der auf der zweiten Sitzung der Lateransynode vorgetragen worden war. ${ }^{219}$ Damit wird der Jerusalemer Beitrag zur Lateransynode ähnlich wie in der überarbeiteten Synopsis stark hervorgehoben. Weisen diese Indizien bereits auf eine palästinische Provenienz der griechischen Vita Martini hin, so machen die weitere Merkmale der Darstellung des VI. Konzils und des Concilium Quinisextum in den Schlusskapiteln 13 und 14 eine palästinisch/Jerusalemer Herkunft mehr als wahrscheinlich. ${ }^{220}$ Dazu gehört auch die exklusive Hervorhebung und Bewertung des Bilderkanons can. 82 des Quinisextums, ${ }^{221}$ die eine Entstehung der griechischen Vita Martini im Kontext des Bilderstreites ca. in der Mitte des 8. Jh.s vermuten lässt. ${ }^{222}$

Damit legen das nach 668 entstandenen Hypomnesticon und die vor 691/2 entstandene überarbeitete Fassung der Synopsis de haeresibus et synodis, von der wiederum die in der ersten Hälfte des 8. Jh.s in Palästina entstandene griechische Vita Martini abhängig ist, sowie der Umgang des Johannes von Damaskos mit den „Prozessakten“ des Maximos Palästina/Jerusalem als Entstehungsort eines Kultes des Maximos und seiner Schüler zusammen mit der Verehrung Papst Martins nahe. Damit wird die These von Roosen bestätigt, dass auch die älteste Vita Maximi in diesen Kreisen entstanden sein wird. Der Kurzfassung dieser Vita, der

214 Conte, Sinodo Lateranense (wie oben Fußnote 93); dazu H. OHмE, Die griechische Vita Papst Martins (BHG 2259), Maximus Confessor und das Concilium Quinisextum (691/2). Byz 86 (2016) (im Druck). Zur Synopsis des Sinaiten s.oben S. 128-130.

215 PeEters, Vie (wie oben Fußnote 212) 254, 7-9. Diese Aussage konvergiert mit der bereits gemachten Beobachtung (s.oben Fußnoten 70 und 93). In maximianischen Kreisen blieb das Wissen lebendig, dass der Initiator der Anathematisierung der Kirche von Konstantinopel und „Schriftleiter“ der Akten der Lateransynode Maximos gewesen ist.

216 PeEters, Vie (wie oben Fußnote 212) 254,16-19.

217 ACO ser. II 1, p. 38, 10 - 46, 36; WinkELMANN (wie oben Fußnote 6) Nr. 82.

218 PeEters, Vie (wie oben Fußnote 212) 254, 25-32. Zu Stephanos vgl. PmbZ, Nr. 6906.

219 ACO ser. II 1, p. 38, 10 - 46, 36 (RIEDINGER).

220 S. dazu im Detail Oнме, Vita (wie oben Fußnote 214).

$221 \mathrm{Zu}$ seiner Bedeutung in der ersten Phase des Bilderstreites s.oben S.139-140.

222 Vgl. dazu OHмe, Vita (wie oben Fußnote 214). 


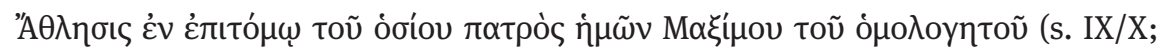
„Compedium Vindobonense“) ist zu entnehmen, dass bereits hier von einer führenden Stellung des Maximos am kaiserlichen Hof in Konstantinopel in frühen Jahren die Rede ist. Die These von RoosEN ist bestechend, dass diese Angabe der im selben geographischen Raum zuvor entstandenen monotheletischen syrischen Vita Maximi ${ }^{223}$ mit ihrem Maximos diskreditierenden Bericht, Kind einer unehelichen Beziehung eines Samaritaners mit einer persischen Sklavin zu sein, entgegengesetzt worden sei. ${ }^{224}$

Mit der offiziellen Rezeption des Maximoskultes in Konstantinopel im 10. Jh. ist der damit einsetzende Vorgang einer byzantinischen „Nostrifizierung“ des „hl. Bekenners Maximos“ anscheinend biographisch vollendet worden, indem Details seiner ersten Lebensjahrzehnte mit vornehmer konstantinopolitanischer Herkunft, höherer Bildung und weltlicher Karriere am Hof hinzugefügt und weitere Einzelheiten und Texte aus Relatio motionis, Disputatio Bizyae, Epistula Maximi ad Anastasium monachum und Epistula Anastasii Apocrisarii ad Theodosium Gangrensem $^{225}$ ergänzt wurden. W. LACKNER hat bereits 1967 nachgewiesen, ${ }^{226}$ dass jene seitdem das Maximosbild bestimmenden Angaben der griechischen Vita (BHG 1234) über Geburt, Jugend und Bildung im 10. Jh. nach dem Muster der Vita des Theodoros Studites ${ }^{227}$ frei gestaltet worden sind.

Diese schließlich erfolgte byzantinische „Nostrifizierung“ scheint durch eine ganze Reihe von Faktoren ermöglicht worden zu sein. Bedeutende zeitbedingte Widerstände waren mittlerweile obsolet geworden. Die Ikonenverehrung wurde zum Normalfall, und Maximos galt nun als Zeuge der Tradition. Die aus apokalyptischer Zeitdeutung erwachsenen politischen und kirchenpolitischen Machenschaften des Maximoskreises waren geschichtstheologisch überholt und konnten mit der dominant gewordenen Deutung ${ }^{228}$ des monenergetisch-monotheletischen Streites durch Anastasios Sinaites und Theophanes Confessor dem Vergessen anheimgestellt werden. Die schwerwiegenden Anklagen in den Pro-

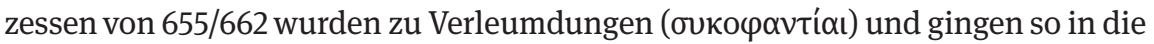

223 Brock, Life (wie oben Fußnote 7).

224 Roosen, Vitae (wie oben Fußnote 7), $432 \mathrm{f}$.

225 Vgl. Neil/Allen, Life (wie oben Fußnote 23) 4-11. 40-44; Boudignon, Maxime (wie oben Fußnote 7); Roosen, Vitae (wie oben Fußnote 7) 440-451.

226 LACKNER, Quellen (wie oben Fußnote 18).

227 Es handelt sich um Recensio A der Vita. Vgl. D. Krausmüller, Vitae B, C and A of Theodore the Stoudite: their interrelation, dates, authors and significance for the history of the Stoudios Monastery in the tenth century: Analecta Bollandiana 131 (2013) 280-298.

228 Vgl. OHмE, Geschichtstheologie (wie oben Fußnote 82) 33-35. 55-61. 
Vita ein. ${ }^{229}$ Die von Maximos propagierte prinzipielle Infragestellung des kaiserlichen Selbstverständnisses als „Kaiser und Priester“ war bereits früh auf kirchenrechtlicher Ebene durch das Concilium Quinisextum zurückgewiesen worden und von den Maximosverehrern innerhalb des byzantinischen Reiches schon modifiziert worden. Entsprechend wird in Recensio II der griechischen Vita Maximi, die eine gekürzte und paraphrasierende Fassung der Relatio motionis bietet, ${ }^{230}$ an dieser Stelle deren Text auch korrigiert. ${ }^{231}$

Ein weiterer erleichternder Faktor bestand in der inzwischen erfolgten breiten Rezeption des maximianischen theologischen Werkes, obwohl dies nicht zu einer Ehrenstellung als „dritter Theologe“ geführt hat. Schließlich mag auch das inzwischen möglich gewordene Eingeständnis kaiserlichen Fehlverhaltens eine Rolle gespielt haben, das Basileios I. (867-886) und Leon VI. (886-912) zu öffentlichen Erklärungen der Buße geführt hatte und in dem Mosaik des „Kaisers als Büßer“ über der kaiserlichen Tür im Narthex der Hagia Sophia ikonographisch Gestalt angenommen hatte. ${ }^{232}$

Es ist also historisch nachvollziehbar, dass ein offizieller Märtyrerkult des Maximos in der Kirche des byzantinischen Reiches erst im 10. Jh. möglich geworden ist, obwohl seine Anhänger und Schüler umgehend nach seinem Tode am 13. August 662 in Propagandaschriften dafür warben und in Palästina/Jerusalem eine solche kultische Verehrung liturgisch installiert wurde. Dem stand aber auch nach 680/81 entgegen, dass die Anklagepunkte des Hochverratsprozesses von 655 und 662 weiterhin als stichhaltig betrachtet wurden. Überdies hatte Maximos alle entgegenkommenden Vermittlungsbemühungen starr zurückgewiesen und war persönlich für die von der Lateransynode im Jahre 649 vorgenommene Anathematisierung der Konstantinopler Kirchenleitung verantwortlich, an der er bis zum Schluss unerbittlich festhielt. Außerdem war die innerbyzantinische Rezeption der theologischen Entscheidung des VI. Ökumenischen Konzils in den Jahrzehnten danach so unsicher, dass sie unmöglich mit einer Rehabilitierung des Maximos zusätzlich belastet werden konnte. Der Maximoskult innerhalb des chalcedonensischen palästinischen Mönchtums war aber auch dort nur auf be-

229 Vita Maximi Rec. II (PG 90, 89B8-C4); Rec. III: 24, 554 (82 NeIL/AlLen).

230 PG 90, 68-109; dazu B. NEIL, The Greek Life of Maximus the Confessor (BHG 1234) and its three recensions. Studia Patristica 36 (2001) 46-53. 52-53.

231 Maximos verneint hier kategorisch, eine Verbindung von Kaisertum und Priestertum prinzipiell bestritten zu haben. Vielmehr habe er gesagt, dass die Definition von Dogmen und deren

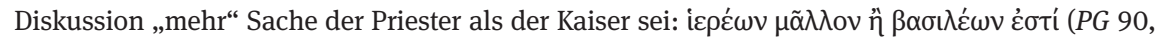
92 A7-C10: C2 - 3). Die dem 11. Jh. angehörende Recensio III der Vita bietet den Text der Relatio motionis an dieser Stelle ungekürzt: Vita Maximi (Rec. III) 55, 1334-1435 (152 NeIL/ALLEN). 232 Vgl. dazu Dagron, Emperor (wie oben Fußnote 88) 114-124. 
stimmte Gruppen beschränkt, zu denen Johannes von Damaskos gehörte. In seinen antiikonoklastischen Schriften erhob dieser Maximos zu einem Traditionszeugen der Bilderfrömmigkeit und aktivierte dessen radikale Polemik gegen das kaiserliche Selbstverständnis als „Kaiser und Priester“ für seine Polemik gegen die bilderfeindliche Religionspolitik Konstantins V. Indem Maximos zum Traditionszeugen der Ikonodulen wurde, war seine Person erneut mit einer langen kirchenpolitischen Kontroverse verbunden, auch wenn seine prinzipielle Infragestellung der kaiserlichen Autorität in kirchlichen Angelegenheiten von den Ikonodulen im Reich stark modifiziert wurde. In ikonodulen monastischen Kreisen der Hauptstadt wird ein partikularer Maximoskult auch innerhalb des byzantinischen Reiches seit der 2. Hälfte des 8. Jh.s praktiziert worden sein. Aber auch nach dem Ende des Bilderstreites gab es im 9. Jh. noch keine einheitliche Bewertung des persönlichen Schicksals des Maximos. Ein Konsens über sein Wirken und Leiden wurde erst in großer historischer Distanz zu den Ereignissen des 7. Jh.s möglich. In diesem Prozess kam es zu einer „Nostrifizierung“ der Person des „hl. Bekenners“, die seine Vita „kreativ“ korrigierte und ergänzte, und damit zu einer hagiographischen Verdunklung der tatsächlichen historischen Umstände des monenergetisch-monotheletischen Streites. ${ }^{233}$

Seit der von H. Delehaye edierten, dem 12. Jh. zugehörenden Fassung des Synaxarium Constantinopolitanum begegnet als eigentlicher Festtag des Maximos

233 Dieses Ergebnis konvergiert mit dem Befund ikonographischer Darstellungen des Maximos. E. VooRdeckers, L'iconographie de Saint Maxime le Confesseur dans l'art des églises de rite byzantin, in A. Schoors / P. van Deun (Hrsg.), Philohistôr. Miscellanea in honorem Caroli Laga Septuagenarii. Orientalia Lovaniensia Analecta, 60. Leuven 1994, 339-359; und P. VAN DeUn, Suppléments à l'iconographie de Maxime le Confesseur dans les arts byzantin et slave, in K. Demoen / J. Vereecken (Hrsg.), La spiritualité de l'univers byzantin dans le verbe et l'image. Hommages offerts à E. Voordeckers à l'occasion de son éméritat. Instrumenta Patristica, 30. Turnhout 1997, 315-331 haben den gesamten Bestand von Miniaturhandschriften, Handschriften mit den Werken des Maximos, Fresken, Kalenderikonen, Privatikonen usw. untersucht. Außer einem halbfigürlichen Medaillon neben zwei Testimonia des Maximos im Cod. Parisinus gr. 923 (s. IX) mit den Sacra Parallela des Johannes von Damaskus (VooRdeCKERs, ebd. 352; VAN Deun, ebd. 316 f.) datieren alle Zeugnisse erst ab dem 11. Jh. Aber auch danach existiert keine einzige Ikone, „où Saint Maxime le Confesseur occupe seul le milieu du champ du paneau [...], et qui aurait été l'icône titulaire sur le registre inférieur de l'iconostase d'une église dédiée à lui““ (VOORDECKERS, ebd. 353). Insgesamt sei eine „pauvreté iconographique“ zu konstatieren, die Voordeckers damit erklärt hat, dass Maximos weder Bischof noch Klostergründer, Hymnograph oder frühchristlicher Märtyrer gewesen sei (ebd. 341). Er sei vielmehr ,avant tout un saint monastique“ gewesen (VAN Deun, ebd. 316). M.E. muss man die in diesem Aufsatz dargelegten Überlegungen nun auch bei der Erklärung der Dürftigkeit dieses ikonographischen „Dossiers“ berücksichtigen. 
der 21. Januar neben seinem Todestag am 13. August. ${ }^{234}$ Diese bis heute bestehende Verschiebung seines Gedenktages in den orthodoxen Kirchen $^{235}$ ist wohl von daher zu erklären, dass der 13. August als sog. Apodosis des Hochfestes der Metamorphosis (6. August) ganz von diesem Festinhalt bestimmt ist. Schwer erklärbar aber

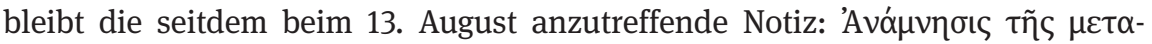

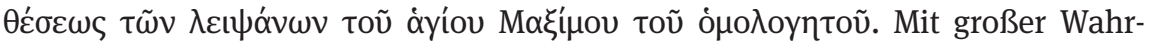
scheinlichkeit ist damit nicht eine Übertragung der Reliquien nach Konstantinopel, sondern in das Kloster des Hl. Arsenios gemeint, das erstmals im sog. Compendium Vindobonense (s. IX/X) als letzter Ruheort des Maximos erwähnt wird. ${ }^{236}$ Dieses in der Nähe der vormaligen byzantinischen Festung $\Sigma \chi \eta \dot{\mu \alpha \rho ı ~ g e-~}$ legene Kloster bei der heutigen georgischen Stadt Tsageri wurde später in Kloster des hl. Maximos umbenannt. ${ }^{237}$ Bemerkenswert ist schließlich, dass es neben diesem georgischen Kloster bis zum Ende des 20. Jh.s kein weiteres orthodoxes Kloster und keine orthodoxe Kirche gegeben hat, die Maximos zu Ehren geweiht wurden. ${ }^{238} \mathrm{Ob}$ man darin einen Rest an Zurückhaltung gegenüber der in vielerlei Hinsicht problematischen Gestalt dieses so bedeutenden Theologen zu erblicken hat?

234 S. oben Fußnote 21; dazu: Roosen, Vitae (wie oben Fußnote 7) 414 Anm. 17.

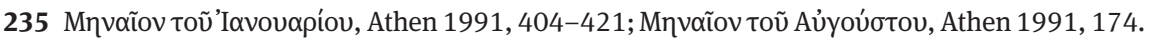
Vgl. dazu auch: VooRdecKers, Iconographie (wie oben Fußnote 233) 340 f.; VAN DeUn, Sppléments (wie oben Fußnote 233) 318-319.

236 Vgl. Roosen, Vitae (wie oben Fußnote 7) 422.

237 K. KeKelidZE. Сведения грузинских источников о препод. Максиме Исповеднике. Trudy Kievskoj duch. akademii 1912, 1-41.451-486; A. BRILliantov, О месте кончины и погребения св. Максима Исповедника. Christianskij Vostok 6 (1917) 1-62.

238 Vgl. Fußnote 233 und das Interview (www.patriarchia.ru/db/text/2034049. html; letzter Zugriff am 23.05. 2015) mit dem Erzbischof von Tsageri und Lentekhi, Stephan, vom 27.02. 2012, in dem er über die Auffindung der Reliquien des Maximos in diesem Kloster berichtet. 